\title{
Comparison of Three Field Methods for Forest Canopy Closure Modelling with Landsat Imagery
}

Submitted by Andrew Mark Lindsay, B.A.

\author{
A thesis submitted to the \\ Faculty of Graduate Studies and Research \\ in partial fulfillment of the requirements \\ for the degree of Masters of Science
}

Department of Geography and Environmental Studies

Carleton University

Ottawa, Ontario, Canada

September, 2005

(C)2005, Andrew Mark Lindsay 


$\begin{array}{ll}\begin{array}{l}\text { Library and } \\ \text { Archives Canada }\end{array} & \begin{array}{l}\text { Bibliothèque et } \\ \text { Archives Canada }\end{array} \\ \begin{array}{l}\text { Published Heritage } \\ \text { Branch }\end{array} & \begin{array}{l}\text { Direction du } \\ \text { Patrimoine de l'édition }\end{array} \\ \begin{array}{l}\text { 395 Wellington Street } \\ \text { Ottawa ON K1A ON4 }\end{array} & \begin{array}{l}\text { 395, rue Wellington } \\ \text { Ottawa ON K1A ON4 } \\ \text { Canada }\end{array}\end{array}$

Your file Votre référence

ISBN: 0-494-10140-7

Our file Notre référence

ISBN: 0-494-10140-7

NOTICE:

The author has granted a nonexclusive license allowing Library and Archives Canada to reproduce, publish, archive, preserve, conserve, communicate to the public by telecommunication or on the Internet, loan, distribute and sell theses worldwide, for commercial or noncommercial purposes, in microform, paper, electronic and/or any other formats.

The author retains copyright ownership and moral rights in this thesis. Neither the thesis nor substantial extracts from it may be printed or otherwise reproduced without the author's permission.
AVIS:

L'auteur a accordé une licence non exclusive permettant à la Bibliothèque et Archives Canada de reproduire, publier, archiver, sauvegarder, conserver, transmettre au public par télécommunication ou par l'Internet, prêter, distribuer et vendre des thèses partout dans le monde, à des fins commerciales ou autres, sur support microforme, papier, électronique et/ou autres formats.

L'auteur conserve la propriété du droit d'auteur et des droits moraux qui protège cette thèse. $\mathrm{Ni}$ la thèse ni des extraits substantiels de celle-ci ne doivent être imprimés ou autrement reproduits sans son autorisation.
In compliance with the Canadian

Privacy Act some supporting forms may have been removed from this thesis.

While these forms may be included in the document page count, their removal does not represent any loss of content from the thesis.
Conformément à la loi canadienne sur la protection de la vie privée, quelques formulaires secondaires ont été enlevés de cette thèse.

Bien que ces formulaires aient inclus dans la pagination, il n'y aura aucun contenu manquant.

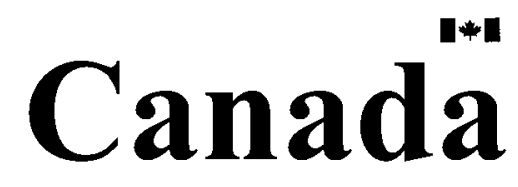




\begin{abstract}
Forest canopy closure is one of the most important structural characteristics linked to the spatial distribution of forest flora and fauna. Quick and cost effective methods are needed to map canopy closure over large areas. This study was designed to evaluate Landsat ETM+ imagery in the modeling of canopy closure in temperate hardwood forests. Three common instruments used to measure canopy closure in the field were compared against each other and then in regression-based modeling using Landsat spectral and spatial information. The three methods of measuring canopy closure were the Trac (Tracing Radiation and Architecture of Canopies), sighting tube and hemispherical photography. It was found that hemispherical photography was the most consistent and least biased method. Use of automated binary thresholding of the hemispherical images was essentially no different than manual thresholding but provided stronger closure models using the Landsat imagery. In modeling canopy closure, it was found that spectral green band data and textural measures of the green and thermal bands had weak but significant relationships with canopy closure. Combined, they produced models of moderate explanatory power (average adjusted $R^{2}=0.40$ for ten models of 25 random samples each) with an average standard error of $7.05 \%$ closure. Validation using 5 plots set aside produced an average error of $-0.23 \%$, and an average absolute error of $6.54 \%$. Although encouraging, these error levels are high in relation to the range of canopy closure in the dataset, which was only about $35 \%$. Better results should be obtainable using higher resolution imagery and in forests of greater variation in canopy closure.
\end{abstract}




\section{ACKNOWLEDGEMENTS}

Funding for this research was provided by an NSERC grant to Dr. D.J. King. Data analysis was conducted in the Carleton University Geomatics and Landscape Ecology Lab, developed by D. King, L. Fahrig, and K. Lindsay with funds from The Canadian Foundation for Innovation, The Ontario Innovation Trust, Carleton University, Ross Hamlin and The Canadian Wildlife Service, Environment Canada. Field equipment was supplied by the Department of Geography, Carleton University. The Trac was generously loaned by Chris Butson of the CCRS (Canadian Centre for Remote Sensing) and the sighting tube by L. Fahrig. Thank you to J.D. Holland for his generosity in providing invaluable information and data pertaining to all the numerous sites that were visited for this study. Access to the numerous plots investigated by the researcher was made with the permission of landowners and farmers too numerous to name.

I am also very grateful to Doug King for his seemingly endless patience, support and time provided during the years that he has served as my thesis advisor. I would also like to thank my lab-mates Jon Pasher, Robbie Bemrose and Amanda Dam for their support in making the lab a work oriented learning environment.

A most sincere thank you to my parents for the unflagging support and funding that they have provided throughout my graduate studies and without whom this thesis might never have been finished. Last, but not least, I would like to thank the RCMP for their understanding of the researcher's needs to be in the woods after dusk and therefore refraining from arresting me as a suspected arsonist. 


\section{TABLE OF CONTENTS}

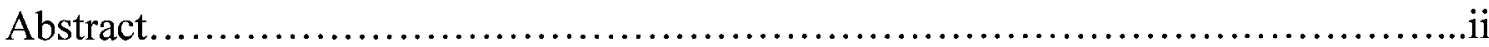

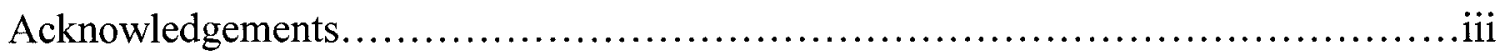

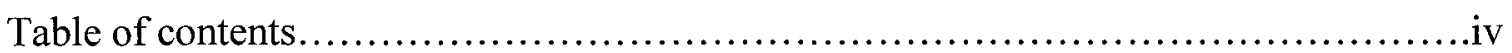

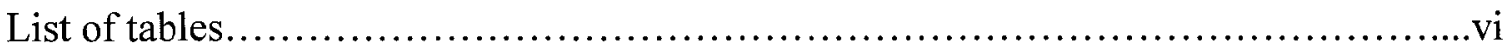

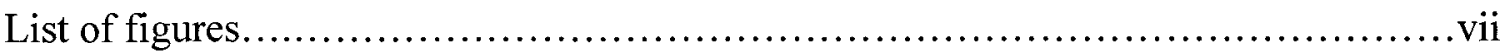

List of equations........................................................................ii

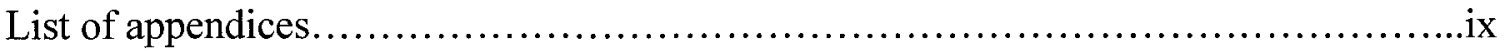

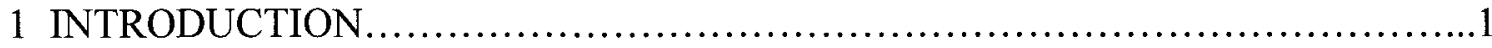

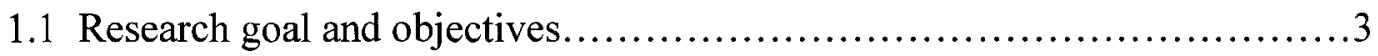

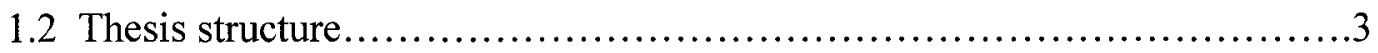

\section{BACKGROUND}

2.1 Canopy closure field instruments.......................................

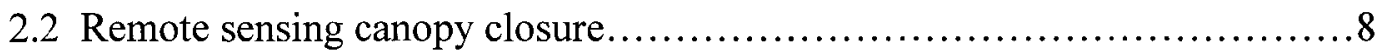

\section{METHODOLOGY}

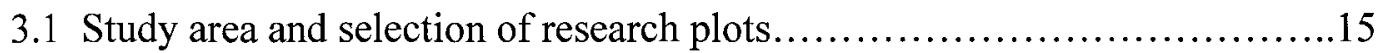

3.2 Field data acquisition and analysis.................................... 17

3.2.1 Acquisition of sighting tube data.............................. 18

3.2.2 Acquisition of Trac data....................................... 18

3.2.3 Acquisition and processing of hemispherical photography data....20

3.2.4 Comparative analysis of the three canopy closure measures.........24

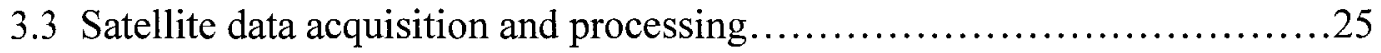

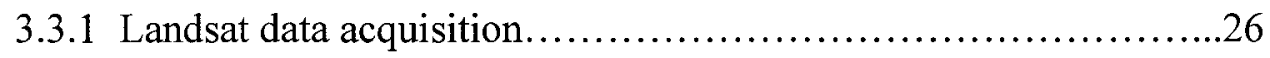


3.3.2 Landsat image mosaicing.

3.3.3 Landsat image geo-referencing................................28

3.3.3.1 GCP data acquisition...............................30

3.3.4 Extraction of spectral and spatial data from the Landsat image.....31

3.3.4.1 Spectral data extraction............................31

3.3.4.2 Spatial data extraction.............................32

3.3.4.3 Data reduction through principal component analysis.....35

3.4 Modeling forest canopy closure using Landsat data.........................

3.5 Model validation.................................................... 37

\section{RESULTS}

4.1 Comparison of the three measures of canopy closure .....................38

4.1.1 Qualitative comparison.....................................38

4.1.2 Quantitative comparison...................................41

4.2 Modeling forest canopy closure using satellite imagery $\ldots \ldots \ldots \ldots \ldots \ldots \ldots . \ldots 50$

4.2.1 Bivariate correlations.....................................50

4.2 .2 Stepwise regression.....................................51

4.2.3 Stepwise regression models using plots set aside for validation....53

\section{DISCUSSION}

5.1 Significant Findings.................................................. 56

5.2 Limitations and Recommendations..................................57

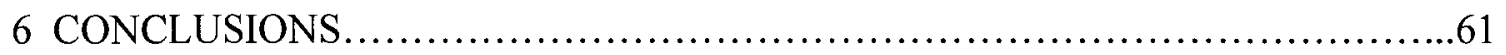

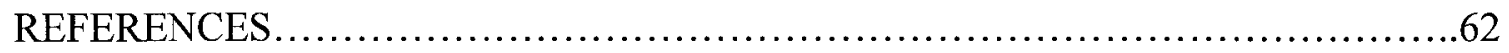




\section{LIST OF TABLES}

1 Bounding rectangle coordinates for the study area............................. 15

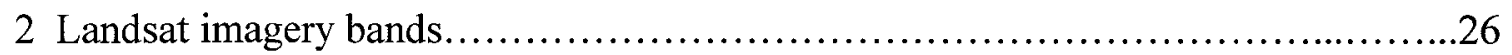

3 Extents of area in which GCPs were taken.....................................

4 Canopy closure estimates derived using each method for all 30 plots...............43

5 Correlation matrix for all methods of canopy closure measurement.................45

6 Bivariate correlations for the textural and spectral image variables against canopy

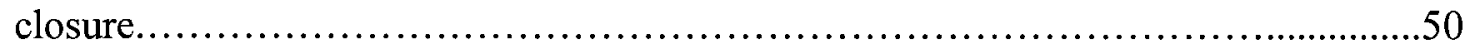

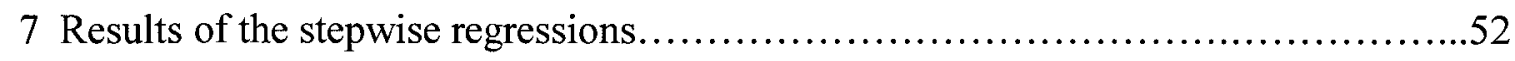

8 Validation of the directed stepwise regressions................................54 


\section{LIST OF FIGURES}

1 Typical reflectance curve for forest canopy vegetation... ........................

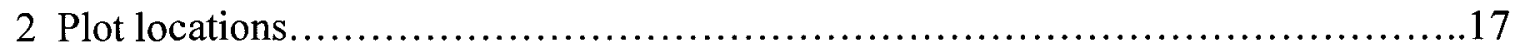

3 Flags denoting a transect................................................ 19

4 Trac measurement in progress............................................. 21

5 Hemispherical photography set-up in the field.................................... 22

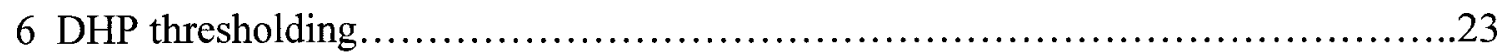

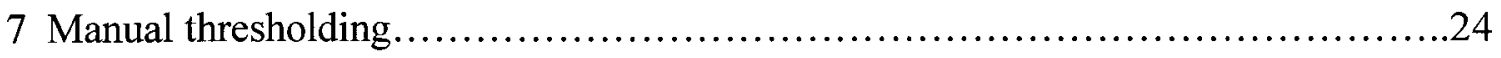

8 A subsection of the two Landsat scenes displayed as a natural colour composite......28

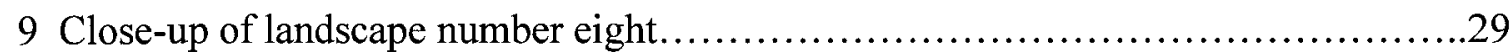

10 Average automated hemispherical canopy closure at 31 degrees vs. Trac canopy closure.

11 Average automated hemispherical canopy closure at 31 degrees vs. sighting tube canopy closure ............................................................49

12 Sighting tube canopy closure vs. Trac canopy closure..........................49 


\section{LIST OF EQUATIONS}

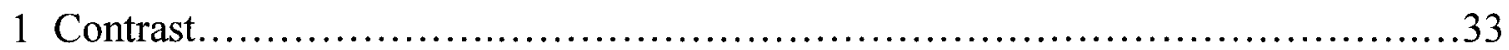

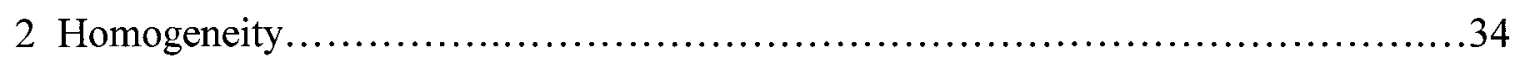

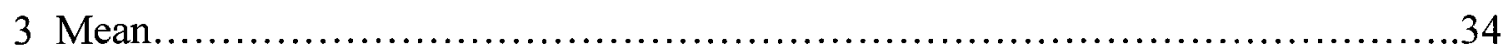

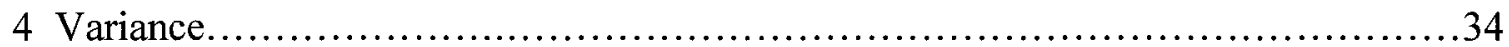

viii 


\section{LIST OF APPENDICES}

APPENDIX 1: Coordinates of the 30 plots used for the study......................69

APPENDIX 2: Tree species noted in plots.......................................... 70

APPENDIX 3: Positions of the 34 points used to perform the orthorectification of the

Landsat image ................................................... 


\section{Chapter 1 Introduction}

Forest canopy closure is the degree to which the forest canopy blocks sunlight or obscures the sky above the forest floor and is usually given as the percent of the total area which is occupied by the crowns of trees (Jennings et al., 1999). It is one of the most important measures in research studies involving flora and fauna in forested environments, often being directly related to where a species will be found (Brown et al., 2000; Bellow and Nair, 2003; Borghesio and Ndang'ang'a, 2003). Many studies have identified forest canopy closure as important with respect to the habitat of both animal and plant species. Wilson and Ference (2001) determined that some forest understory plants (most notably indicator species) have very narrow ranges of habitat and that the percentage of forest canopy closure can sometimes determine their location. Canopy closure is also very important with respect to forest dwelling animals in wildlife modelling (Ohmann, 1992; Hodson et al., 2004) and species habitat analysis (Swallow et al., 1988; Thomas et al., 1990; Reynolds et al., 1992; Grubb et al., 1997). In addition, it is an important component in studies of productivity (Hollenstein et al., 2001), physical processes such as evapotranspiration (Worledge et al., 1998), and forest fire modeling and management (Schmidt et al., 2002).

Traditionally, canopy closure has been measured at field sites using instruments that record closure in a local area. In landscape ecology, spatially explicit representation of canopy closure over large regions is required to aid development of understanding of relations of species abundance and persistence with forest structure. Interpolation to produce spatial representations of forest structure can be used with point measurements if sufficient field samples are available to represent the spatial variability. 
Alternatively, remote sensing provides imagery representing canopy reflectance that is spatially explicit, but it is not a direct means of canopy closure measurement. It is necessary that models of closure be developed that relate point field measurements to image characteristics. The models are then applied to the remaining image coverage to produce a map canopy closure. Acquisition of field data is labour intensive and expensive while remote sensing can provide data for a much lower cost per unit area. This research used moderate resolution Landsat imagery because of its low cost, large coverage, which is suitable for regional and landscape scale mapping, and because analysis of the literature indicated that little research had been conducted in forest canopy closure mapping using Landsat.

This thesis compares three field instruments in measurement of forest canopy closure: $a$. to each other, and b. in modelling canopy closure with Landsat imagery. The sighting tube is used to visually determine whether sky or foliage is seen when viewing vertically. Hemispherical photographs detect diffuse sky radiation versus dark leaves and branches, while the Trac (Tracing Radiation Architecture of Canopies) measures direct sun rays in proportion to shadows cast by leaves and foliage. More detail on each instrument is given in Chapter 2. It is evident that these three instruments measure ground level radiation in different ways. Therefore, it is relevant to determine whether or not the results from the three instruments are comparable in measuring forest canopy closure. Following this, a study of the capability to model forest canopy closure using Landsat ETM+ spectral and spatial information was conducted. Canopy closure measured by the three instruments was again compared in this modeling experiment. 


\subsection{Research Goal and Objectives}

The goal of this research was to determine if forest canopy closure measured using common optical methods can be modeled accurately using Landsat ETM+ imagery. The two main objectives were:

- To implement a field study to compare three different instruments for measurement of forest canopy closure.

- To statistically model forest canopy closure measured by these instruments using the spectral and spatial information in satellite imagery.

The three instruments selected for this study were:

- Sighting tube

- Trac (Tracing Radiation and Architecture of Canopies) and

- Hemispherical photography.

\subsection{Thesis Structure}

This thesis is organized into six chapters. Chapter One contains the introduction, research goal and objectives as well as the thesis structure. Chapter Two provides the background to the thesis with respect to the instruments used to measure canopy closure and discussed the potential of remote sensing in mapping closure. Chapter Three presents the research methods, including the study area, plot sampling design, the methods used to measure forest canopy closure in the field, the processing of these data, the acquisition and processing of the remotely sensed imagery, and the modeling of canopy closure against the image variables. The results of these analyses are the focus of Chapter Four. Chapter Five provides a discussion of the significant findings of this research, problems encountered during the study and recommendations on how they might be addressed in future research. Chapter Six provides conclusions for the research. 


\section{Chapter 2 Background}

\subsection{Canopy Closure Field Instruments}

Methods that are used to measure canopy closure can be categorized as: 1 . point based measurements where canopy closure is determined in a binary manner using observed records of whether foliage or sky exists overhead at a single point on the ground, 2. hemispheric optical methods measuring the amount of foliage and sky in a given view angle from vertical, and 3. line transect measurements where gaps are either measured as sunflecks (direct sun rays penetrating the canopy) or using active laser sensing to determine the edges of gaps. To review the range of available instruments, a description of how examples within each category function is given below. In this research, one instrument from each of the categories was used.

The Moosehorn, canopy scope, spherical densiometer and sighting tube are used to visually estimate the proportion of overhead gaps in the forest canopy. One of the oldest instruments for visual estimation is the Moosehorn, developed by Robinson (1947). It is a type of scope with a grid that is projected vertically at several locations in the forest. Canopy closure can be estimated by taking the average of several observations of whether gaps or foliage are visible within a given area (e.g. 20 measurements in 0.1 ha) (Vales and Bunnell, 1985; Jennings, 1999). Canopy-scopes are similar instruments but are more robust and portable, measuring the largest canopy gaps visible (vertically or obliquely) from the point of observation rather than just directly overhead. They can be used to measure canopy closure where the canopies have greater than approximately $70 \%$ closure. The instrument is a transparent square piece of glass or plastic that has a grid of 25 dots etched at $3 \mathrm{~cm}$ intervals. At each sample location, the number of dots 
unobstructed by forest canopy is counted. An average of eight to ten measurements must be made in a 0.25 ha plot for an accurate measurement of canopy openness (Brown et al., 2000; Borghesio and Ndang'ang'a, 2003; Hale and Brown, 2004). Spherical densiometers consist of mirrored hemispherical domes with dots etched in a grid on their surfaces. The instrument is held at elbow height in the palm of the hand and oriented in such a way that the observer can view the forest canopy above. At each sample location, the number of points on the graticule where the canopy is open is counted. Four estimates at any one point are made in each of the cardinal directions with the average of these four measures constituting the forest canopy openness. Again, averaging for several sample locations is necessary to obtain a representative estimate (Englund, 1999; Bellow and Nair, 2002). A sighting tube is a piece of PVC pipe with crosshairs at the end that also works in a binary fashion. When the instrument is oriented vertically, the crosshairs will either be positioned on foliage or sky. When the crosshairs intersect on foliage, the sighting is described as a hit whereas if the crosshairs intersect at a point where the sky is visible the sighting is described as a miss. Forest canopy closure (\%) is therefore calculated as the number of hits divided by the total number of sightings multiplied by 100 (Darwin et al., 2004).

The second category of instruments uses hemispheric optics. It includes nonimaging instruments such as the Li-Cor LAI-2000 plant canopy analyzer. A hemispheric light detector is used to measure diffuse irradiance both underneath the canopy and in the open (the reference of $0 \%$ closure). Total gap fraction is derived from the ratio of these two measurements and converted to canopy closure (100\% - \%gap fraction) or used to derived leaf area index (LAI) (Welles, 1990; Comeau, 1998; Machado and Reich, 1999; 
White et al., 2000; Rhoads et al., 2004), the total one-sided area of leaf tissue per unit ground surface area (Brenda, 2003). LAI has been used in numerous forestry studies many of which involve its correlation with satellite imagery for mapping purposes (Chen et al., 2002; Hall et al., 2003; Fernandes et al., 2004). However, further discussion of LAI and LAI mapping is beyond the scope of this thesis. In contrast, hemispherical photography provides an image of the overhead canopy. Images are taken at dusk or dawn (to record only diffuse light) during calm wind conditions. A thresholding method is used to separate the diffuse sky radiation from the darker leaves and branches in the image. The total gap fraction, which is the percentage of sky seen in the image (Martens et al., 1993) is calculated by counting the number of sky pixels in proportion to the total number of pixels in the view angle. The gap fraction is then subtracted from $100 \%$ to achieve the forest canopy closure.

The third type of instrument directly measures the gap size distribution from either sunflecks and shadows projected through the canopy, or using active lasers pointed through the canopy. The former includes the sunfleck ceptometer which is a battery operated PAR (photosynthetically active radiation) sensor on a hand-held wand. It is placed at various locations under the canopy and the ratio of recorded sunflecks to shadows is used to determine the canopy closure (Decagon Devices, 1987; Wang, 1999; Balaster and Marshall, 2000; Pocewicz et al., 2004). The Trac is an irradiance sensor, similar in concept, that was developed specifically to measure LAI. The light detector is fixed to a small tube with an attached microprocessor and memory. By walking along a transect perpendicular to the sun azimuth, a continuous signal is recorded ( 32 readings per second) of the radiance incident to the sensor. The Trac software uses a thresholding 
method to determine which sections of the signal represent sunflecks and which represent shadows. From the relative proportions of each, the gap fraction in the direction of the sun can be calculated and converted to percent canopy closure (Martens et al., 1993). Direct field measurement of gaps can also be achieved with lasers although they are more suited to airborne scanning as described in Section 2.2.

In comparing the three methods of measuring canopy closure from the ground, it is important to understand the interaction between the sensor viewing geometry and structure of the forest canopy. The sighting tube has a very narrow angle of view and therefore is subject to possible bias by the way it is held by the observer. If it is not held perfectly vertically, incorrect readings can be taken. Also, many small vertical gaps in the canopy can really bias the measurements of canopy closure. The Trac detects sun rays at the oblique sun zenith angle (about 32 degrees in this study) which pass through longer path lengths than either the sighting tube or hemispherical photography. The increased path length also means that spatially heterogeneous canopy structure (uneven upper canopy or variable understory structure) will have a greater effect on the measurements than for the other two instruments. Finally, for horizontally oriented leaves, the increased leaf projection angle at the view angle of the Trac will result in detection of more shadow than would be detected vertically. Both the path length and leaf projection angle are larger than in the vertical direction by the cosine of the zenith angle. Thus, closure measurements are expected to be greater using the Trac than for the other two instruments. Hemispherical photography is integrated over angles from vertical to that specified by the user but are usually quite narrow. However, angles larger 
than 20 degrees include some oblique angles that would be expected to result in higher canopy closure measurements due to the factors listed above.

Previous studies done by students at the Carleton University Geomatics and Landscape Ecology Laboratory have used the sighting tube, the Trac, and hemispherical photography. Since these methods are well documented and representative of the three types of forest canopy closure technology described above, they were compared in this research.

\subsection{Remote Sensing of Canopy Closure}

All field methods for visual and optical measurement of closure are either very time consuming or provide estimates of canopy closure at sample points only. Remote sensing has the potential to measure canopy closure over a spatially extensive area faster and at a low cost. With this in mind, it would be beneficial to landscape ecologists and biologists alike to have a method with which to determine the percentage forest canopy closure over specific regions within a large area. High and moderate resolution satellite and aerial imagery (with pixel sizes ranging from $2 \mathrm{~cm}$ to $5 \mathrm{~m}$ ) have been used to determine specific characteristics of forested areas such as density, forest type (species composition), forest structure, timber stocking, and canopy closure (Gemmell, 1995; Worledge et al., 1998; Hollenstein et al., 2001; Wilson and Ference, 2001; Schmidt et al., 2002).

Healthy green vegetation, such as leaves in a forest canopy typically displays a spectral reflectance curve, similar to that shown in Figure 2. The peaks and valleys depicted show the parts of the electromagnetic spectrum where energy is mainly reflected or absorbed, respectively. In the visible spectrum, from approximately 0.4 to $0.7 \mu \mathrm{m}$, 
leaves appear green because energy is absorbed at 0.45 and $0.67 \mu \mathrm{m}$ respectively (the first two valleys in Figure 2) due to chlorophyll absorption. Absorption is lower in the region of $0.55 \mu \mathrm{m}$ (green), thus reflectance is higher (the first peak) than in the red and blue portions of the spectrum.

The second peak represents the near-infrared (NIR) part of the electromagnetic spectrum, 0.76 to $1.30 \mu \mathrm{m}$, where up to $50 \%$ or the incident radiation can be reflected. This is due to the internal structure of the leaves which make up the canopy. The two remaining peaks indicate the increases in reflectance between the three remaining valleys which represent water absorption bands at $1.4,1.9$ and $2.7 \mu \mathrm{m}$ respectively (Lillesand and Kiefer, 2000).

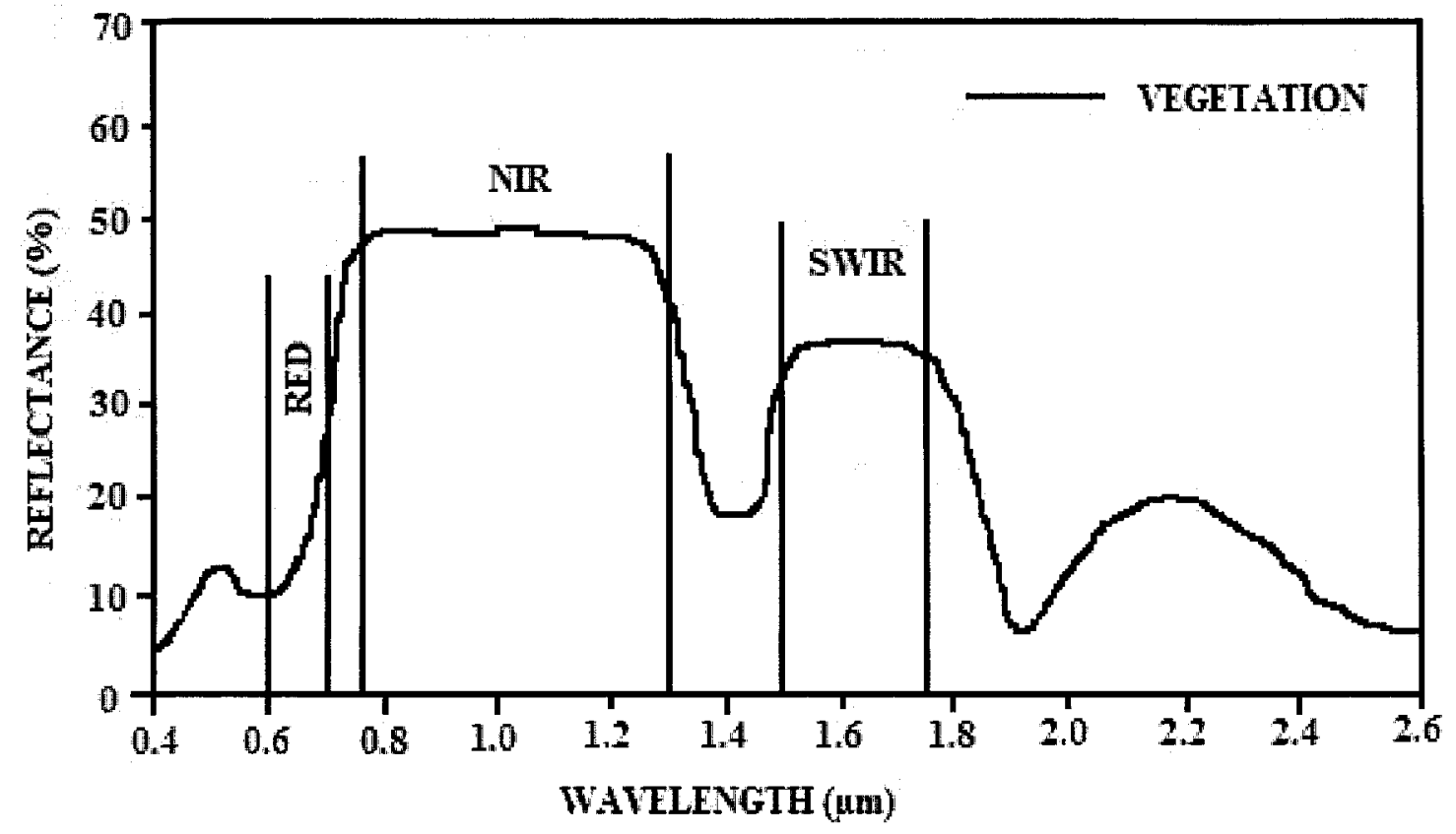

Figure 1. Typical reflectance curve for forest canopy vegetation.

According to this graph, it is probable that the spectral bands that would have the most potential for canopy closure estimation would be the NIR and red. Where vegetation cover is high, the NIR band should be bright while in the red, it should be 
darker than other land cover types. However, the increasing relationship of NIR reflectance with vegetation cover is known to begin to saturate at LAI of about four and maximum NIR reflectance is reached at approximately eight leaf layers (Breda, 2003).

The following review of past remote sensing of canopy closure begins with the airborne sensors followed by the moderate resolution Landsat satellite sensor. Aerial photography has long been used to study forest canopy closure and cover as well as other vegetation structural attributes. It can produce data of higher resolution than almost all other sensors from which the height, width and health of individual tree crowns can be studied. Aerial photography has primarily been used in the past to conduct forest inventory (tree species, stocking and timber volume estimation) through stereo visual interpretation. However, high resolution photographs also allow for a number of other forest canopy attributes to be analysed, such as forest gaps, shadows and overstory. Pellikka et al. (2000) used aerial CIR photography and hemispherical photography to model deciduous forest ice storm damage, closure and basal area in Gatineau Park, Quebec. It was demonstrated that hemispherical photographs were a relatively simple, repeatable and low cost method of deriving both effective $\mathrm{LAI}\left(\mathrm{LAI}_{\mathrm{e}}-\right.$ which assumes a random leaf distribution) and canopy closure. Significant relationships were derived between these field attributes and spectral and spatial air photo variables. Fensham et al. (2002) made a quantitative assessment of vegetation structural attributes from aerial photography. They evaluated the influences of photo-scale (1:25 000 and 1:40 000), photo colour , image angle, shadow, time difference between aerial and field sampling, crown width, crown height, land type and other parameters on explanatory models and found that only photo-scale and land type were useful for predictive models. Two-phase 
models were also produced which were successful for predicting overstory and understory closure as well as total basal area and biomass over long time periods.

Airborne digital camera imagery can also be used to assess the same attributes as aerial photography but digital cameras are less costly, and imagery can be viewed, verified for ground coverage, and interactively adjusted to optimize exposure in-flight. Pellikka (2001) used wide-angle vertical photography in conjunction with airborne video data for phenological studies of beech forests in the German Alps. There was a strong correlation between canopy closure estimation and the vertical photography with $\mathrm{R}^{2}$ values ranging from 0.72 to 0.88 . However, it was also shown that the estimations of canopy closure are difficult to compare with spectral information acquired through these remotely sensed data because, of all four spectral bands used (Blue, Green, Red, and NIR), only the red band produced a significant correlation of $\mathrm{R}^{2}=0.72$.

Lévesque and King (2003) used airborne digital camera imagery to model individual crown and forest canopy structure through the use of radiometric fractions combined with spectral and textural data. Of three pixel sizes tested $(0.25,0.5$, and 1.0 $\mathrm{m}), 0.5 \mathrm{~m}$ was found to produce the best models of closure and other forest variables. Cosmopoulos and King (2004) integrated canopy closure with other structure and health variables in a multivariate forest structure condition that was well modeled $\left(\mathrm{R}^{2}\right.$ of 0.66$)$ using digital camera spectral and spatial data. Haddow et al. (2002) used airborne digital camera imagery with $2.5 \mathrm{~cm}$ pixels to assess and identify early regeneration conifers and their competition. This study indicated that there was strong potential for modeling closure of canopies comprising competing deciduous and young coniferous vegetation. 
Another technique that is currently expensive and limited to airborne remote sensing is measurement of canopy closure using either laser profiling or lidar (light detection and ranging, which are both active techniques. Simple laser profiling is only able to obtain canopy elevation data (Krabill and Maclean, 1984; Moore et al., 1999) along a transect directly underneath the aircraft. Scanning, multiple-return lidar on the other hand is able to measure a swath of the ground per flight line. The field of view can be set from 1 to 75 degrees and the swath of land which can be profiled depends on the height at which the system is being operated. From an airborne platform, lidar is a technology that uses rapid pulses $(15,000$ pulses per second) of laser light to strike the surface of the earth and to measure the time of the pulse return. By timing the return of each laser pulse, the distance between the ground and the sensor can be calculated. Lidar can distinguish upper canopy from understory because up to five returns per pulse can be recorded. In addition, it is able to distinguish snow from asphalt and other surfaces depending on the intensity of the light being reflected back to the sensor. Over a forest canopy, a lidar sensor might record up to 135,000 points per square kilometer due to the multiple returns from each pulse (Lillesand and Kiefer, 2000; Lefsky et al. 2004). Through the above studies it can be seen that good models of forest canopy closure and other structure characteristics can be developed using high resolution sensors. However, applications are limited to small local areas due to high costs and the time required for processing large data sets that are needed to cover larger areas. To model forest canopy closure in a cost-effective and timely fashion over larger areas, some resolution must be sacrificed. Landsat is a moderate resolution sensor with 30 m pixels and coverage of about $180 \times 175 \mathrm{~km}$ per scene that is continuously collecting data almost 
worldwide and that is readily available to researchers at low cost. Since it was first launched in 1972, successive improvements have been made and the most recent sensor, Landsat ETM+, launched in 1999, has seven bands through the visible and infrared sections of the electromagnetic spectrum. It has been used for a variety of aquatic and terrestrial applications, but most commonly for land-cover mapping.

In forest canopy closure mapping, Archibald (1987) used delineated forest polygon band means, stand age, slope and aspect to develop a multiple regression model for a small stand of lodgepole pine. Accuracy achieved was $85 \%$ for $10 \%$ crown closure classes, although the area mapped was small. Woodcock et al. (1994) used Landsat TM and an invertible forest canopy reflectance model to map forest cover types (conifer, hardwood and brush) on a per-pixel basis which yielded general-purpose vegetation maps with accuracies of up to $86 \%$. Gemmell (1995) studied the effects of forest closure, terrain and scale on timber volume estimation using Landsat TM and achieved moderate results; inventory volumes of between $150 \mathrm{~m}^{3} /$ ha and $300 \mathrm{~m}^{3}$ / ha were correctly identified with an accuracy of $78 \%$. However, for timber volumes of less than $150 \mathrm{~m}^{3} /$ ha the accuracy fell to $44 \%$. Gemmell et al. (2001) then estimated closure in a boreal forest using Landsat data from two dates. Correlations between closure and spectral reflectance using the differences between dates for the red and MIR bands were higher $((\mathrm{R}<0.56)$ and $(\mathrm{R}<0.64)$, respectively) than for single date imagery $(\mathrm{R}<0.47)$. Finally, Gemmell et al. (2002) attempted to estimate boreal canopy closure and crown transparency (a function of crown leaf area index) using Landsat and some ancillary data (crown cover and transparency measured using five vertical digital multispectral photographs per plot) but achieved very limited results. The factors behind this were the 
effects of noise in the TM data and errors in the ancillary information. Pu et al. (2003) estimated subpixel closure in oak forests using artificial neural networks (ANN) as well as an unconstrained least squares solution (LLS) method combined with spectral unmixing of Landsat TM data. Fractions of endmembers (oak crown, grass, soil and shade) from mixed pixels were derived and two spectral unmixing algorithms were compared. It was found that the best results were obtained without the use of the shade endmember and that the shadow problem caused by topography would have to be resolved before the shaded side of the hills could be used for crown closure estimation.

The results from these studies using Landsat imagery indicate that it is an effective tool for classifying canopy closure over densely forested areas but that it becomes less reliable as the forest becomes less dense (Gemmell, 1995). Landsat is also very effective in research studies that broadly classify cover over large areas or study homogeneous land classes (such as plantation or boreal forests) over smaller areas but it has not yet been used to study large areas where the forest is quite dense but less homogeneous in terms of tree species. Landsat could be a useful tool for measuring canopy closure over large areas using broad general classification categories. Other technologies could then be used to more accurately measure canopy closure for areas of interest identified through this preliminary Landsat application. 


\section{Chapter 3 Methodology}

\subsection{Study Area and Selection of Research Plots}

The study region for the research was Eastern Ontario where mature forests are predominantly mixed hardwood with some coniferous trees. A set of 30 research areas (landscapes), previously established by the Department of Biology at Carleton and within driving distance of Ottawa, was used. Each landscape $(1 \mathrm{~km}$ by $1 \mathrm{~km})$ comprised 10 plots. These plots had been located within the landscapes in order to provide the greatest cross-section with respect to canopy closure and extant tree species for that study. They were initially used for the placement of beetle traps and the forested plots were later used in ice storm research in which forest canopy closure had been measured with a sighting tube (Darwin et al., 2004).

From the 30 landscapes, all of which had similar species of trees and forest maturity, 24 were selected that were located within two Landsat images. The bounding rectangle of the 24 landscapes is shown in Table 1.

Table 1. Bounding rectangle coordinates for the study area.

\begin{tabular}{|l|l|l|}
\hline \multicolumn{1}{|c|}{ Corner } & \multicolumn{1}{|c|}{$\begin{array}{c}\text { North Latitude } \\
\text { (degrees, minutes) }\end{array}$} & \multicolumn{1}{c|}{$\begin{array}{c}\text { West Longitude } \\
\text { (degrees, minutes) }\end{array}$} \\
\hline South East & $45^{\circ} 08^{\prime}$ & $76^{\circ} 07^{\prime}$ \\
\hline North East & $45^{\circ} 26^{\prime}$ & $76^{\circ} 07^{\prime}$ \\
\hline South West & $45^{\circ} 08^{\prime}$ & $76^{\circ} 21^{\prime}$ \\
\hline North West & $45^{\circ} 26^{\prime}$ & $76^{\circ} 21^{\prime}$ \\
\hline
\end{tabular}

The southeast corner was near the town of Carleton Place and the northwest corner was at Arnprior. Owners of the land on which plots were located within the 24 landscapes were contacted and 11 gave permission for the researcher to be alone on their land throughout the day and at dusk. Since none of the landscapes straddled property boundaries, this meant that 110 plots could be investigated. All of these plots except for 
three (which could not be found) were scouted. Since they had been previously used as sites where beetles were collected, not all of them were within forest patches ( 16 were in fields), which left 91 viable plots with previously estimated forest canopy closures of between 40 and 100 percent. These were further assessed for suitability based on the following criteria:

a) inclusion of the greatest possible range of forest canopy closure

b) little or no vegetation between about $1.5 \mathrm{~m}$ (the camera height) and $10 \mathrm{~m}$ to minimize its effect on canopy closure estimation and on image modeling,

c) ease of access for transport of the required equipment and ease of instrument installation and use, and

d) a minimum of $30 \mathrm{~m}$ between plot boundaries to ensure lack of spatial overlap in the Landsat $30 \mathrm{~m}$ pixels and in the hemispherical images.

Only 79 of the 91 plots met these criteria. A random sample of 30 plots was chosen from these 79 in order to achieve a balance between time available and statistical viability. These 30 plots represented seven of the 11 landscapes. The plot locations are shown in Figure 2. Appendix 1 gives coordinates of the plots.

The plots were predominantly mixed-age hardwood forest stands which contained 21 tree species (see Appendix 2). The most dominant of these were Sugar Maple, White Ash, Eastern White Pine, Trembling Aspen, American Elm and a more intermediate species, Ironwood. All these sites were on flat terrain with a maximum slope of approximately $10 \%$. Previous measurements of canopy closure using a sighting tube ranged from $60 \%$ to $100 \%$ (Charbonneau and Fahrig, 2004). 


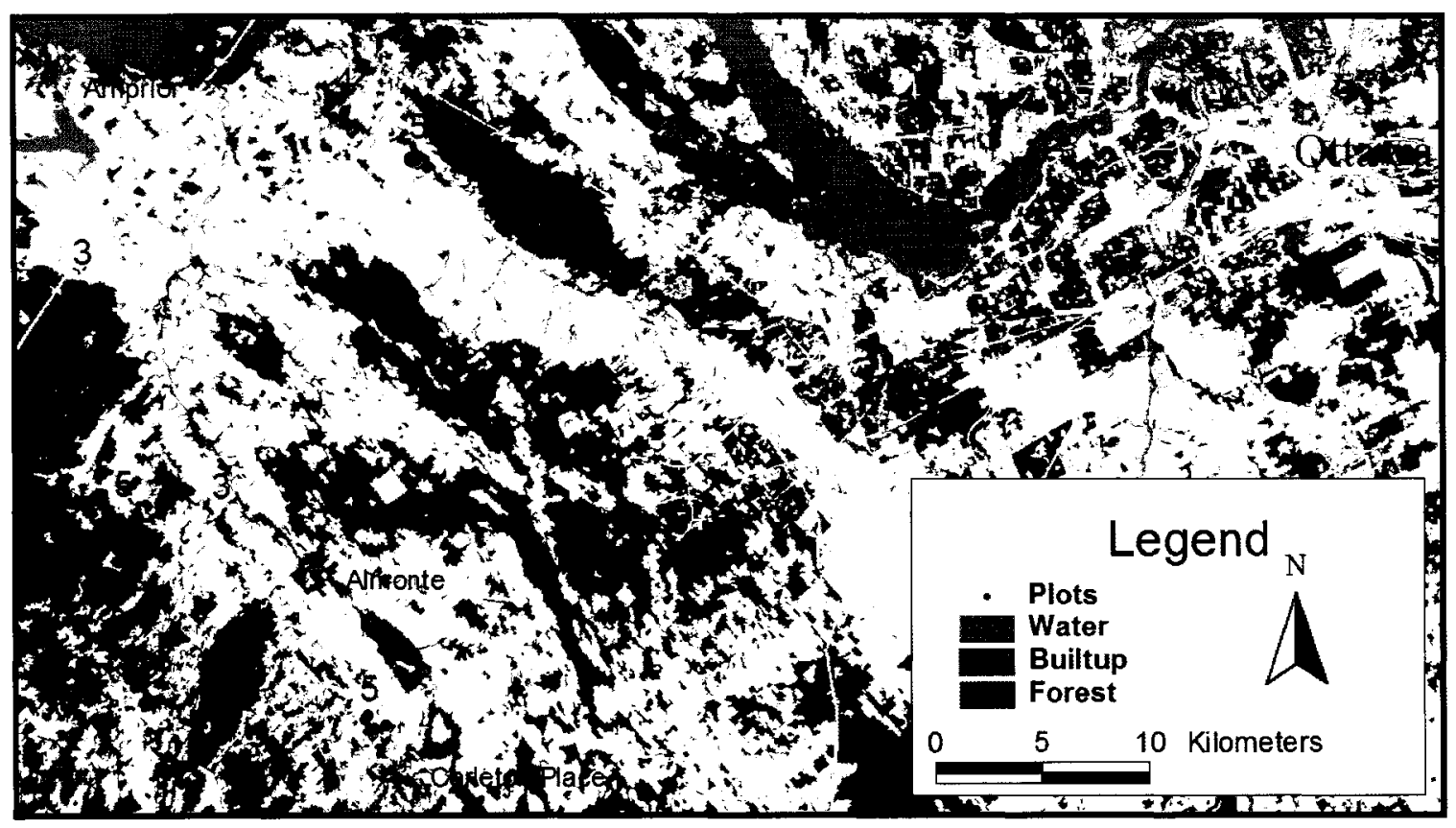

Figure 2. Plot locations. Numbers denote the number of plots in each landscape.

\subsection{Field Data Acquisition and Analysis}

The first objective of this research was to estimate and compare forest canopy closure using three optical instruments: a sighting tube, the Trac and hemispherical photography. All of the field work was conducted between mid July and late August, 2002.

As it was necessary to navigate to each plot, often at dawn and dusk for hemispherical photography, the position of each plot centre was recorded using differential GPS. These positions were used to locate the plots in the satellite imagery in the subsequent canopy closure modeling stage. From each plot centre, boundaries of 30 $\mathrm{m}$ by $50 \mathrm{~m}$ were delineated with the $50 \mathrm{~m}$ axis oriented east - west. Three $50 \mathrm{~m}$ east west transects were installed in each plot (along both outside edges of the plots and along a centre line) with flags being placed every five metres using a chain rope and a compass. 
This meant that each transect had 11 flags (including those on the perimeter) for a total of 33 per plot. A flagged transect can be seen in Figure 3.

Measurements with all three instruments were made in each plot on the same day for $90 \%$ of the plots to ensure that conditions within the forest did not change during the observation period. For three plots, observations were made the following day due to conditions such as high winds or rain.

\subsubsection{Acquisition of sighting tube data}

The sighting tube was pointed vertically toward the forest canopy at each flag, with an additional reading taken at the end of the transect, in order to have 30 measurements in each plot. Each time the observer looked through the sighting tube, a notation was made of a hit or a miss. A hit meant that the crosshairs at the end of the PVC pipe (the tube) had intersected on foliage. A miss meant that the crosshairs had intersected at a point where the sky was visible. The forest canopy closure (\%) could then calculated as the number of hits divided by the total number of sightings multiplied by 100 .

\subsubsection{Acquisition of Trac data}

Trac data acquisition was conducted along each of the three transects in each plot between the hours of 1100 and 1300 EDT (Eastern Daylight Time) when the sun was highest in the sky and when there were no clouds or haze between the sun and the sensor. The instrument was held horizontally at elbow height (approximately $110 \mathrm{~cm}$ above the ground; see Figure 4) and all three transects were traversed at approximately 0.3 metres per second. At each flag, a time marker was added to the data. Following data 
acquisition, the data were downloaded directly to a laptop computer to check that no errors had been made in their collection.

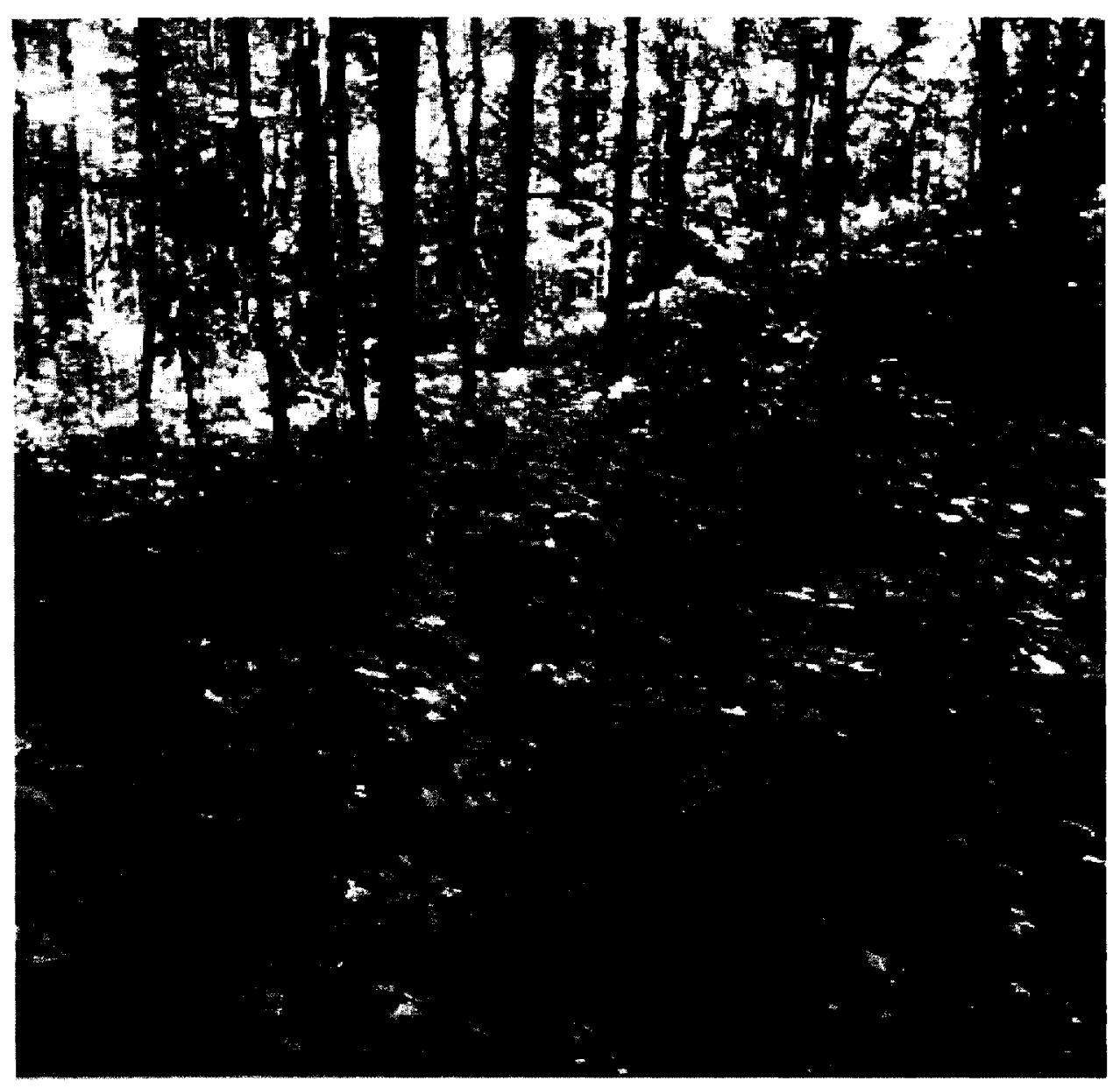

Figure 3. Orange flags (circled) denoting a transect.

Trac data were processed with TracWin software developed at the Canada Centre for Remote Sensing (Leblanc et al., 2002). All 30 sections of data between the time markers (flags) that made up the three transects of a plot were combined into one value of gap fraction. This was then converted to canopy closure. 


\subsubsection{Acquisition and processing of hemispherical photography data}

Hemispherical photography can be used to measure the percentage of forest canopy closure through the use of a binary image of vegetation and sky. As with the Trac, a thresholding method is used to determine what part of the photo is foliage or woody components and what part is sky (within a given angle from the zenith).

Acquisition of the hemispherical imagery was slightly more involved than the sighting tube and the Trac as it required precise timing, more equipment, and greater setup time. A Nikon Coolpix 990 digital camera, mounted with a Nikon Fisheye FC-E8 lens, was positioned on a tripod at the northeast, southwest and centre of each plot. The long axis of the camera was always north - south in aspect with the back of the camera pointing east and the lens being level and at a height of $175 \mathrm{~cm}$ (Pellikka et al., 2000). The images were taken just after dusk and, in a few cases, just before dawn to ensure a uniform sky background with no sun flecks reflecting off leaves. Several images with different shutter speeds were taken to ensure that at least one photo had an optimal exposure at each location within a given plot. Figure 5 shows the camera-tripod set-up.

An evaluation was made of all the images taken within each plot. The photos that were too dark (i.e. it was difficult to distinguish between leaves and sky) were deleted as well as those that were too bright (i.e. photos which had light blooming around the leaves). Therefore, only those photos with close to perfect exposure of diffuse sky were chosen. The photos were then split into their respective channels (red, blue, and green) using Photoshop 6.0. In the imagery, the sky appears bright. Therefore, it is essential that the foliage appear as dark as possible with respect to the sky so that it is possible to clearly differentiate between the two. The foliage appears darker when the blue channel 
alone is used because almost all the radiation with a blue wavelength $(0.4$ to $0.5 \mu \mathrm{m})$ is absorbed by the foliage.

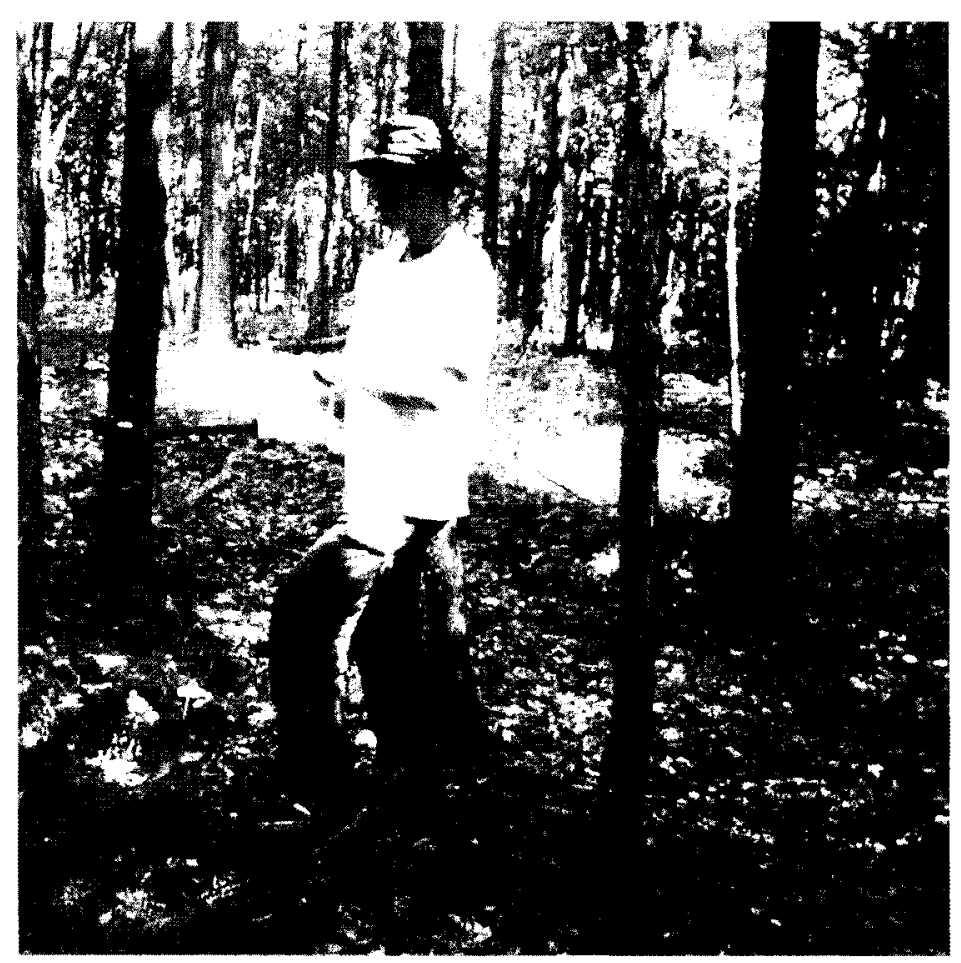

Figure 4. Trac measurement in progress.

Incident radiation with red $(0.5$ to $0.6 \mu \mathrm{m})$ or green $(0.6$ to $0.7 \mu \mathrm{m})$ wavelengths is not absorbed as readily by foliage making it appear brighter in the image. Therefore, the blue channel was chosen for further analysis as it had the greatest contrast of the three bands between sky and foliage/branches (Butson C., pers. comm.). Digital hemispherical photo (DHP) software developed by NRCan/CCRS (Natural Resources Canada / Canada Centre for Remote Sensing) was used to process and analyse the images. Four concentric rings called zenithal annulus segments were established with zenith angles of $0-4^{\circ}, 0-13^{\circ}, 0-22^{\circ}$ and $0-31^{\circ}$, respectively. 


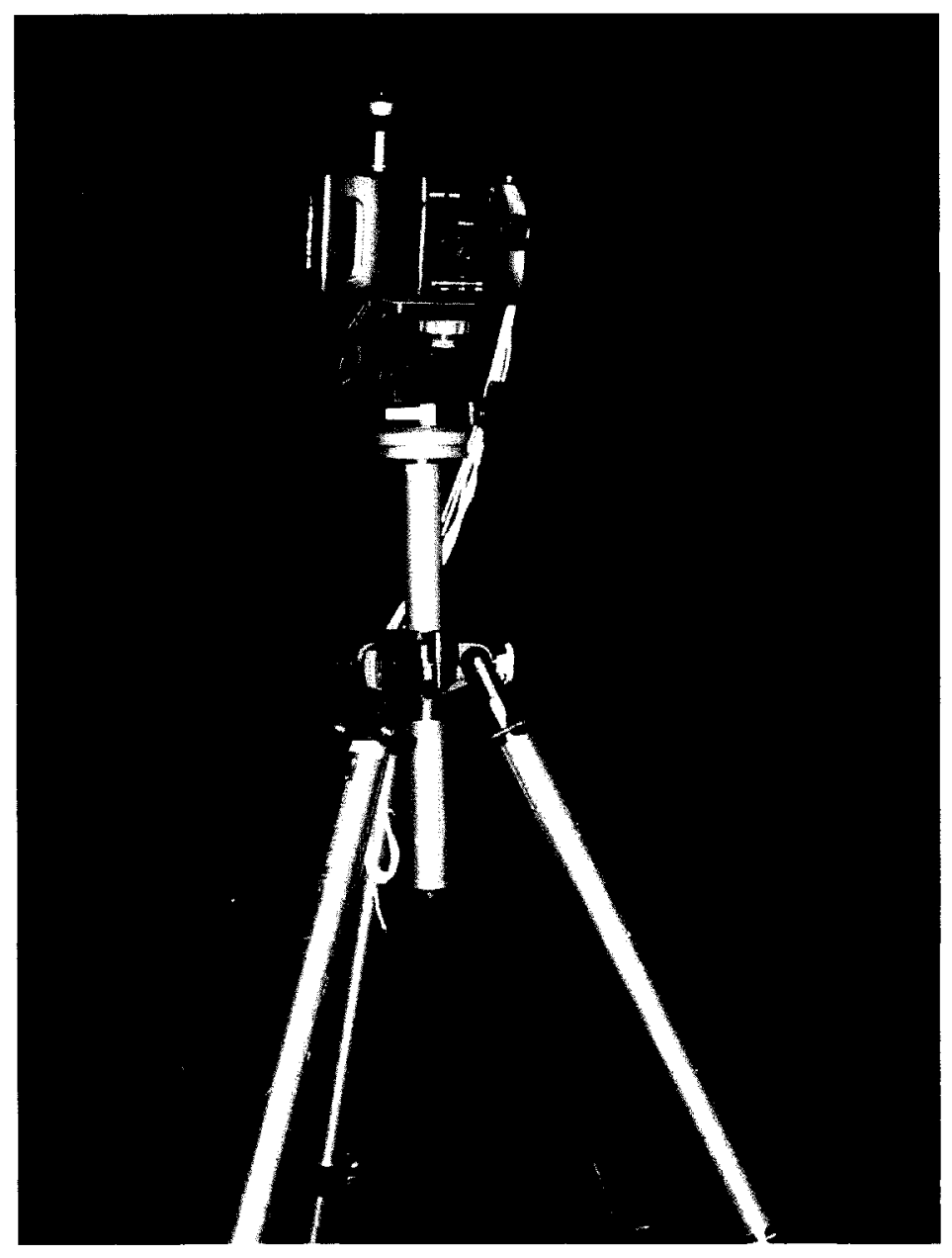

Figure 5. Hemispherical photography set-up in the field. Courtesy of J. Pasher.

The $0-31^{\circ}$ angle was of particular interest because the diameter of the forest canopy imaged in this angle $\left( \pm 31^{\circ}\right)$ was also $30 \mathrm{~m}$ (for trees of approximately $25 \mathrm{~m}$ height), which is the same size as one Landsat pixel.

DHP's interactive image classification was used to create a histogram of all the DN (brightness) values found within each zenithal annulus segment. This histogram was used twice for each segment to adjust the threshold intensity value which trains the program on how to distinguish sky from foliage. 


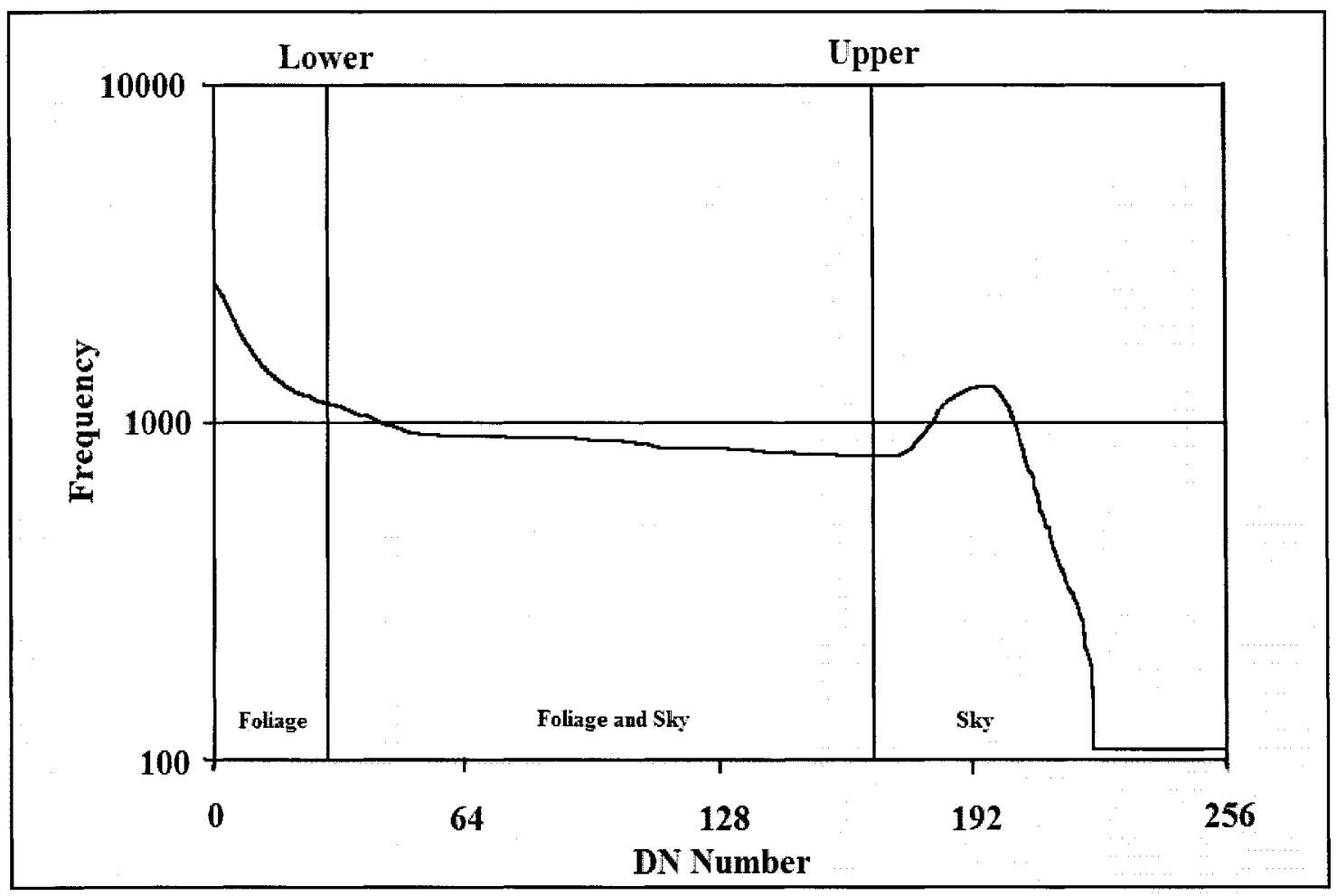

Figure 6. DHP thresholding.

The first thresholding of the histogram was determined in an automated manner by the software where the low threshold is the most frequently occurring DN below 75 (to which 30 grey levels are added) and the high threshold is the most frequently occurring DN above 75 minus 15 levels. The remaining pixels that have not been classed are split equally between foliage and sky. These high and low thresholds are used to separate pure and mixed pixels (Leblanc, 2004). Figure 6 represents an example of DHP thresholding.

Because it was thought that a more accurate threshold could be found by the researcher, a second threshold for each zenithal annulus segment was determined manually. The upper and lower thresholds were positioned where the researcher deemed 
the linear behaviour of the histogram to start and stop, respectively (Butson C., pers. Comm.). Figure 7 represents an example of manual thresholding.

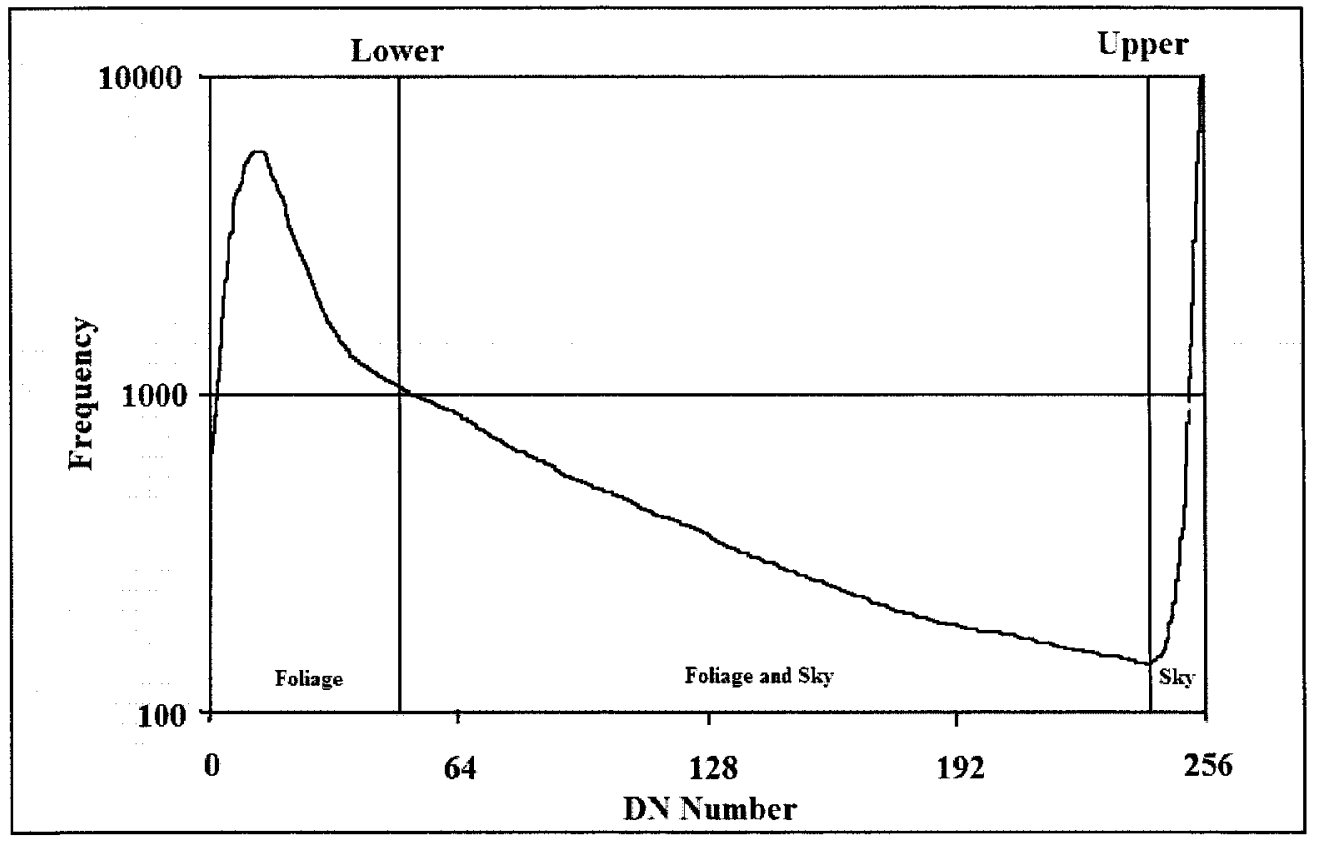

Figure 7. Manual thresholding.

These two threshold methods were applied to each of the four rings for each of the three photos in each plot. Canopy closure was then derived from these thresholds by dividing the number of pixels classified as foliage by the total number of pixels and multiplying by 100 to calculate the percentage canopy closure. The three values of closure for each plot were then averaged. The final data set consisted of average closure estimates for each plot in the four rings for each of the two threshold methods.

\subsubsection{Comparative analysis of the three canopy closure measures}

The three canopy closure measurement techniques were compared both qualitatively and quantitatively. In the qualitative comparison, an assessment was made of their relative advantages and limitations for each of the following operational aspects 
in order of importance: 1) the nature of the data acquired; 2) environmental constraints; and 3) ease of data acquisition planning, set-up, field measurement, and data processing. Quantitatively, the three methods were compared through correlation and regression analysis and then in modeling using Landsat imagery.

It was assumed in this research that there was a uniform structure to the forest canopy over space and that the leaves within the canopy were generally horizontal in orientation. In deriving closure from the hemispherical photography and the Trac data, a mathematically derived correction for path length was not attempted (e.g. Chen and Cihlar, 1995) as it was only of interest to compare the raw closure values and the interaction of path length with spatial heterogeneity in the forest. That is, overlapping of crowns, mutual shading of trees due to variability in tree height over space, and variations in leaf orientation are factors that would either compound or reduce the path length effect. Based solely on viewing geometry, the oblique angle for hemispherical photography varied from just off nadir to $31^{\circ}$ degrees and for the Trac, the angle was fixed at the sun zenith of about $32^{\circ}$. The cosines of these angles are 0.86 and 0.85 , respectively, meaning that the bias due solely to path length for hemispherical photography varied from $0 \%$ at nadir to $14 \%$, and was fixed at about $15 \%$ for the Trac. For the $0-22^{\circ}$ hemispherical photography, the bias was less than $7 \%$. The sighting tube measurements were taken vertically and therefore no action would need to be taken with respect to their path length through the canopy.

\subsection{Satellite Data Acquisition and Processing}

Landsat 7 ETM+ was used in this study for a variety of reasons. The first is that it has a large coverage $\left(30,000 \mathrm{~km}^{2}\right.$ per scene) and therefore a large area can be imaged in 
relatively few scenes. Landsat also costs much less than high resolution imagery and other moderate resolution satellite data such as SPOT. Landsat has a good track record since it has previously been used successfully in studies involving forest type, canopy closure and structure modeling (Woodcock et al., 1994; Gemmell, 1995; Turner et al., 1999; Eklundh et al., 2003) as described in Chapter 2. Table 2 shows the spectral bands of the Landsat data.

Table 2. Landsat imagery bands.

\begin{tabular}{|l|l|c|c|c|}
\hline Band & \multicolumn{1}{|c|}{ ETM+ Sensor } & $\begin{array}{c}\text { Bands } \\
\text { Used }\end{array}$ & $\begin{array}{c}\text { Nominal } \\
\text { Ground Pixel } \\
\text { Size (m) }\end{array}$ & $\begin{array}{c}\text { Bandwidth } \\
(\boldsymbol{\mu m})\end{array}$ \\
\hline $\mathbf{1}$ & Blue & $\mathrm{X}$ & 30 & $0.45-0.52$ \\
\hline $\mathbf{2}$ & Green & $\mathrm{X}$ & 30 & $0.53-0.61$ \\
\hline $\mathbf{3}$ & Red & $\mathrm{X}$ & 30 & $0.63-0.69$ \\
\hline $\mathbf{4}$ & NIR (Near Infra-Red) & $\mathrm{X}$ & 30 & $0.75-0.90$ \\
\hline $\mathbf{5}$ & MIR (Mid. Infra-Red) & $\mathrm{X}$ & 30 & $1.55-1.75$ \\
\hline $\mathbf{6}$ & TIRLG (Thermal Infra-Red, Low Gain) & $\mathrm{X}$ & 60 & $10.4-12.5$ \\
\hline $\mathbf{7}$ & TIRHG (Thermal Infra-Red High Gain) & & 60 & $10.4-12.5$ \\
\hline $\mathbf{8}$ & SWIR (Short Wave Infra-Red) & $\mathrm{X}$ & 30 & $2.10-2.35$ \\
\hline $\mathbf{9}$ & Panchromatic & $\mathrm{X}$ & 15 & $0.52-0.90$ \\
\hline
\end{tabular}

$\mathrm{ETM}=$ Enhanced Thematic Mapper

\subsubsection{Landsat data acquisition}

To obtain full coverage of the study area, two scenes were required, corresponding to path 16 , rows 28 and 29 . Of all the scenes available (as viewed on USGS Earth Explorer web site: http://edcsns17.cr.usgs.gov/EarthExplorer/), those for August 28, 2002, (Figure 6) were essentially cloud-free and haze-free. The Row 29 scene had some haze in the lower left corner but it was selected because this haze did not enter into the study area and because it was deemed better to have two cloudless, sameday scenes at the end of the time frame than scenes from two dates where one was partly 
cloudy. This would ensure that relative radiometric matching of the two scenes could be easily accomplished.

These spectral bands were combined into two PCI (.pix) image files. The high gain thermal band was not used because the information within it is the same as for band 6 but amplified by a gain control, and it tends to saturate in some locations. (www.gael.fr/eoqc/site/documents/download/GAEL-P157-SLP-001-04-01.pdf) All subsequent processing of the Landsat imagery was conducted using PCI Geomatica software. Figure 9 shows a close-up of landscape eight which is the uppermost landscape in Figure 2, and which contains four plots.

\subsubsection{Landsat image mosaicing}

An analysis was made of the overlapping area to see if it was necessary to perform a radiometric calibration on the two scenes. The two scenes had been taken on the same day, almost simultaneously. There was virtually no difference between the individual brightness (DN) numbers of single pixels in any of the eight bands within the overlapping area. It was therefore decided that no radiometric normalization would be carried out on the two scenes. The two scenes were mosaiced together using PCI's GCP Works. Seventeen points were selected in the overlapping area and a linear affine transformation was conducted to align them (Lillesand and Kiefer, 2000).

After the two images were mosaiced, a rectangular area which included all the plots of the study area was clipped out for further processing. 


\subsubsection{Landsat image geo-referencing}

As topographic variation within the study area was negligible, complete orthorectification was not required. The imagery was geo-referenced to a UTM coordinate system using the GCPs described in the next section. Thirty-four points were used because six could not be accurately found on the mosaiced Landsat image.

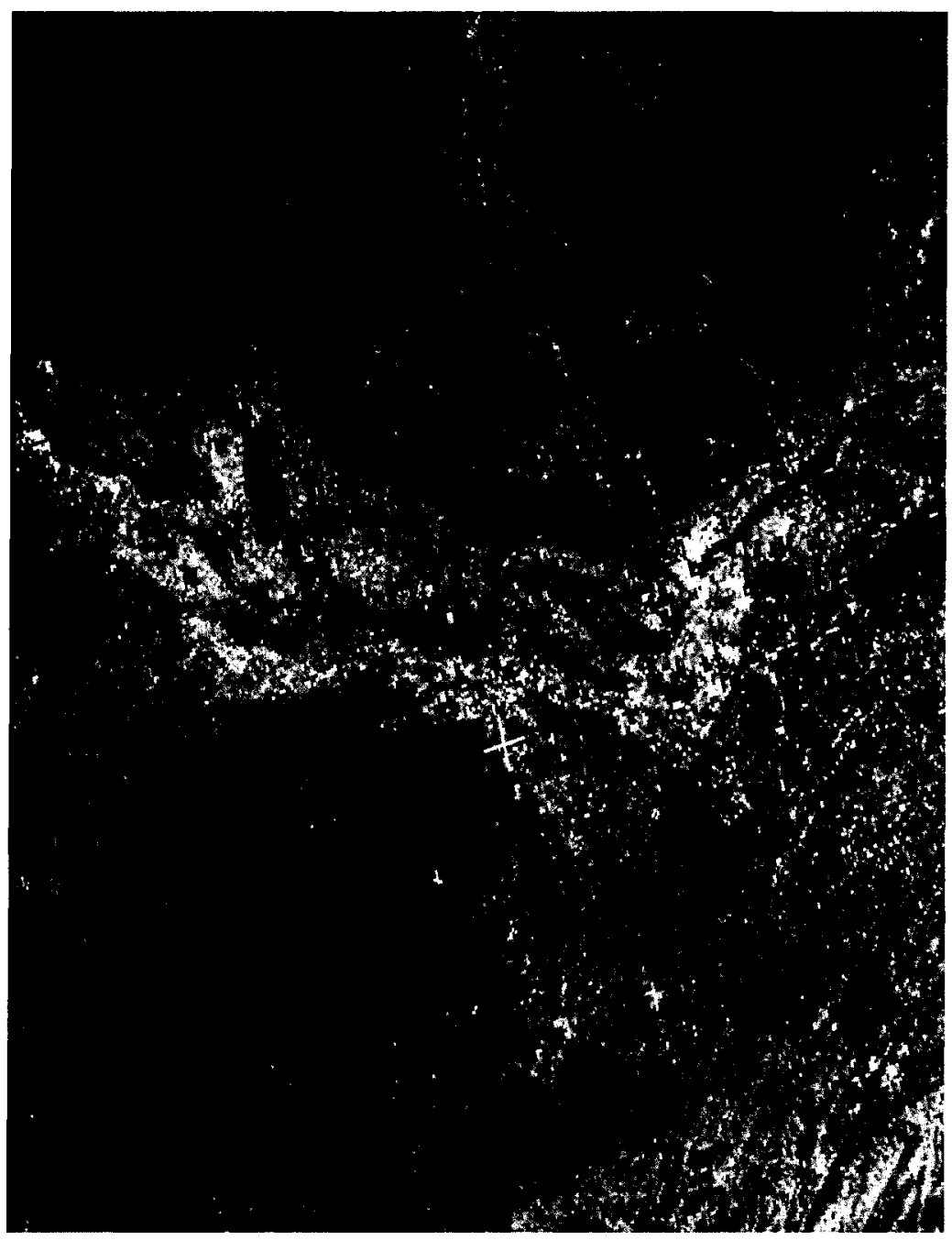

Figure 8. A subsection of the two Landsat scenes displayed as a natural colour composite (blue, green, red spectral bands displayed as blue, green, and red colours, respectively). 
Geo-referencing involves the geometric transformation of an arbitrary grid of image pixels to a planimetric coordinate system. The transformation is derived from a set of image sample points whose coordinates on the ground are known (Lillesand and Kiefer, 2000).

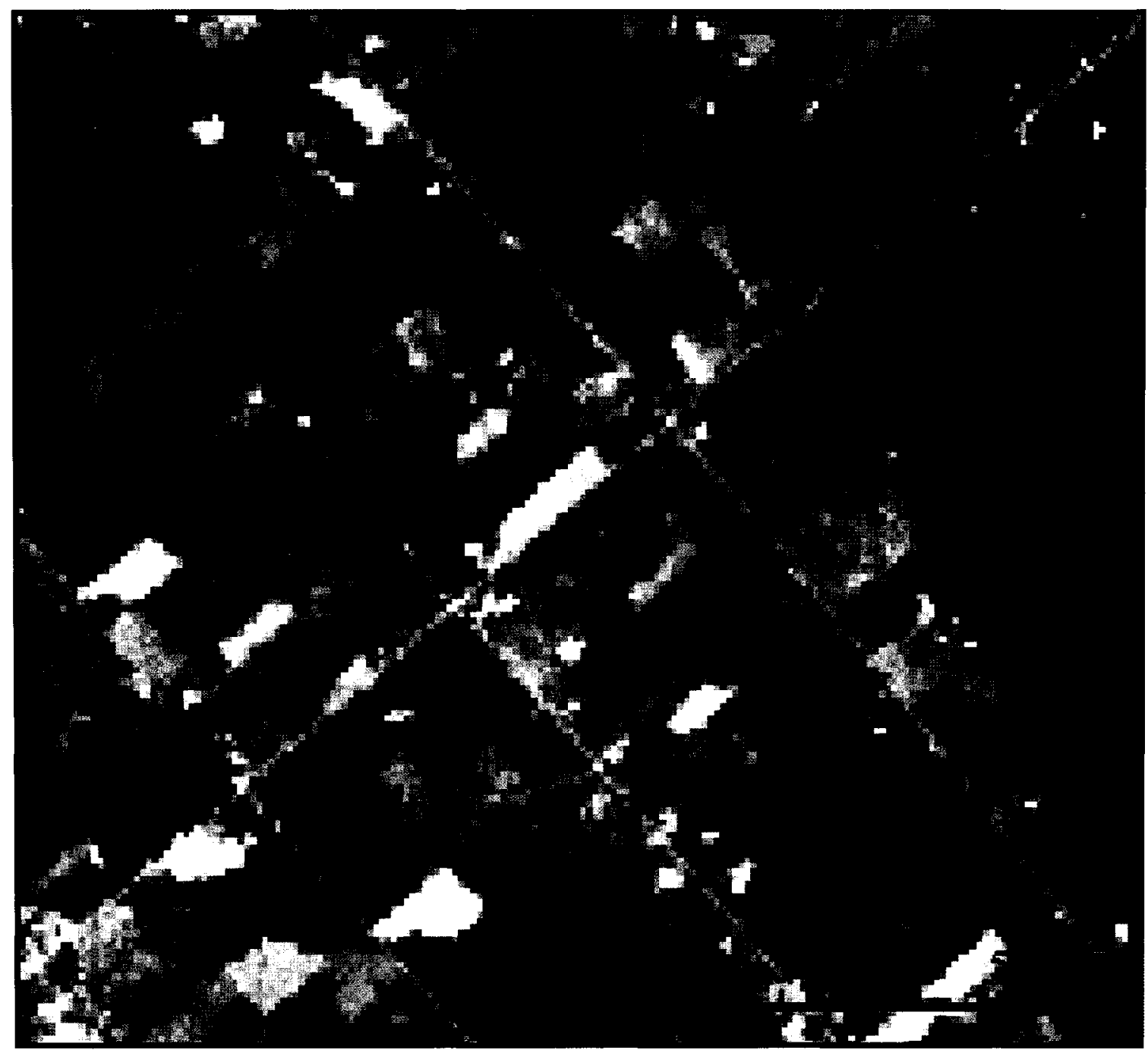

Figure 9. Close-up of landscape number eight. Numbers denote the number of the plot.

In this case it was done using a first-order polynomial co-linear transformation that corrected for scaling in both the $\mathrm{x}$ and $\mathrm{y}$ axes, resulting in an RMS error of $0.15 \mathrm{~m}$ (1/2 pixel) for the sample points in both the $\mathrm{x}$ and $\mathrm{y}$ directions. 


\subsubsection{GCP data acquisition}

The acquisition of GCPs was done using a Trimble GeoExplorer GeoXT

handheld GPS (Global Positioning System) in conjunction with a car-mounted, magnetic, external-patch antenna. A total of 40 positions were taken in an area slightly larger in all directions than the actual study area in order to eliminate any edge discrepancies which would occur if geo-referencing was done using GCPs taken only within the study area. The extents of this larger are shown in Table 3.

Table 3. Extents of area in which GCPs were taken.

\begin{tabular}{|c|c|c|}
\hline Corner & $\begin{array}{c}\text { Latitude } \\
\text { (degrees, minutes, seconds) }\end{array}$ & $\begin{array}{c}\text { Longitude } \\
\text { (degrees, minutes, seconds) }\end{array}$ \\
\hline South East & $45^{\circ} 05^{\prime} 34.30$ & $75^{\circ} 5924.38$ \\
\hline North East & $45^{\circ} 2802.38$ & $75^{\circ} \overline{5924.38}$ \\
\hline South West & $45^{\circ} 0534.30$ & $76^{\circ} 2251.62$ \\
\hline North West & $45^{\circ} 2802.38$ & $76^{\circ} 2251.62$ \\
\hline
\end{tabular}

The locations of these points are shown in Appendix 2. The GCPs were chosen around a loose grid of the township, concession and side road system to ensure accurate and even distribution throughout the area. A GCP was taken at each major road intersection as well as at other positions such as bridges, dams and railroad crossings identified with the aid of a 1:50,000 NTS map. These points were chosen with 30 metre square pixels in mind since all these types of points would be relatively easy to identify on the Landsat image.

At each of the 40 locations, an average of 60 individual readings (one per second) were taken to ensure high accuracy. PCI software allows specification of sub-pixel locations in the selection of GCPs so that precision greater than the $30 \mathrm{~m}$ pixel size of Landsat imagery can be obtained. Each point was taken with no fewer than six satellite signals and a PDOP of 2.5. PDOP is the "position dilution of precision", a unitless figure 
of merit expressing the relationship between the error in user position and the error in satellite position. Small PDOP values, such as those of this study, are associated with well separated satellites and indicate good positioning for triangulation of the operator's position (giswww.pok.ibm.com/gps/glossary.html).

3.3.4 Extraction of spectral and spatial data from the landsat image

For modeling of forest canopy closure using the Landsat imagery, variables representing both spectral and spatial image information were extracted using the processes described below.

\subsubsection{Spectral data extraction}

Spectral reflectance has been shown to be related to forest canopy closure (Woodcock et al., 1994; Yang and Prince, 1997). In this study, once the mosaic was georeferenced, the locations of each of the 30 plots were found in the imagery. The brightness (DN) values for all seven bands were then extracted for the pixel in which each plot was found. In addition, the average brightness of a $3 \times 3$ pixel sample $(90 \mathrm{~m} \times$ $90 \mathrm{~m}$ ) centred on each plot was taken for comparison to single pixel values in regressionbased modeling of canopy closure. This comparison was conducted because it was not known whether forest canopy closure measured in the plots would be more related to single pixel brightness or to average canopy brightness in the local area around each plot. Larger sample areas were not tested because some plots were only about $50 \mathrm{~m}$ from a forest edge. Since the study plots were relatively small $(30 \mathrm{~m}$ x $50 \mathrm{~m})$, larger sample areas would have included data far outside the plots. 


\subsubsection{Spatial data extraction}

The most common quantitative representation of spatial image information that has been utilized in remote sensing is image texture. Based on studies which have successfully used a combination of Landsat imagery and spatial texture analysis to study forestry (Kiema, 2002; Asner et al., 2002; Franklin et al., 2003), it was expected that canopy reflection heterogeneity over a local area of $90 \times 90 \mathrm{~m}$ could be related to the overall canopy closure of the forest.

Texture can be defined as the differences or variations in brightness levels over space in an image (Lillesand and Kiefer, 2000). If there is a large difference in DN values between adjacent or closely situated pixels, the texture is high whereas if there is little or no difference between closely situated pixels, the texture is low.

Texture in digital imagery is quantitatively assessed using a variety of texture measures. The most common types of texture measures are computed through the use of a Grey Level Co-occurrence Matrix (GLCM). A co-occurrence matrix shows the relationship between the $\mathrm{DN}$ value of a given pixel and the $\mathrm{DN}$ values of its neighbours within a defined window. The GLCM is simply a tabulation of the frequency of all possible combinations of pixel brightness values for all possible sample pairs of pixels in the selected window. In most texture algorithms, the frequencies are converted to probability of occurrence. From the GLMC, a variety of texture measures has been proposed (e.g., Haralick et al., 1973). Each represents some sort of two dimensional variance property of the image. Texture is calculated for each pixel by moving the window through the image. The window stops at each pixel, the GLMC is derived, and the selected texture measures are calculated. Upon completion, the window is transferred 
to the next pixel and the process is repeated. In this way, texture is determined for every pixel in the image except image-border pixels where the window cannot extend outside the image. Several texture measures were calculated for each plot and the results were then extracted to be used as data input in forest canopy closure regression modeling.

The texture measures used were Angular Second Moment, Contrast, Correlation, Dissimilarity, Entropy, Homogeneity, Mean and Variance. Each was calculated at a window size of $3 \times 3$ on each of the seven spectral bands creating a total of 56 texture measures.

Summarized definitions of these measures are as follows (Haralick et al., 1973; PCI Inc. Geomatica Manual) with some equations (Hall-Beyer, 2004):

- Angular Second Moment: This is a measure of local homogeneity and the opposite of Entropy. It is low when the local window has pixels that differ greatly in DN values; high when pixels have very similar DN values (i.e. it decreases with increasing texture).

- Contrast: This represents the amount of local variation and is the opposite of Homogeneity (when high numbers of pixel occurrences concentrate along the diagonal). Contrast is weighted by the squared difference in adjacent pixel values ( $i$ and $j$ ) and is therefore very responsive to sudden changes in brightness over space such as often occur at the edges of objects. See equation 1.

$$
\sum_{i, j=0}^{N-1} P_{i, j}(i-j)^{2}
$$

- Correlation: This measure analyses the linear dependency of grey levels of neighbouring pixels. It is typically high, when the scale of local texture is larger than the selected distance between pixels (i.e. when texture is low in the window). 
- Entropy: This measure is calculated using the classic formulation for entropy by multiplying the probability of a given pair of brightness values by the (-)log of their probability. It is low when the values of the local window have similar values (low texture) and high when the values differ greatly.

- Dissimilarity: Similar to Contrast, it is high when the local region has a high contrast.

- Homogeneity: Also called Inverse Difference Moment, it is the opposite of Contrast as the squared differences between DN values are in the denominator. It is high when pairs of pixel values concentrate along the diagonal of the GLCM, thus representing low texture. This occurs when the image is locally homogeneous. See equation 2.

$$
\sum_{i, j=0}^{N-1} \frac{P_{i, j}}{1+(i-j)^{2}}
$$

- Mean: Mean does not simply represent the average grey level in the window but uses a GLCM so that the pixel value is weighted by its frequency of occurrence in combination with its neighbour pixel values. See equation 3.

$$
\sum_{i, j=0}^{N-1} j\left(P_{i, j}\right)
$$

- Variance: This is similar to the statistic by the same name. It relies on the mean and dispersion around the mean of the DN values within the co-occurrence matrix window. See equation 4 .

$$
\sigma_{i}=\sqrt{\sum_{i, j=0}^{N-1} P_{i, j}\left(i-\mu_{i}\right)^{2}}
$$

The variance calculated by the equation would be the same if $j$ were used in the equation instead of $i$ because the matrix used is symmetrical. 


\subsubsection{Data reduction through principal component analysis}

Canopy closure modeling was conducted with all the spectral and textural variables but, since there were 63 of them, a Principal Component Analysis (PCA) was also employed to reduce the data dimensionality. PCA is used to reduce a large set of variables down to a few which together represent most of the information found in the original large set of variables (Chapman et al., 1993). To accomplish this, linear transformations are derived that form new orthogonal (uncorrelated) data axes (the principal components or PCs) with each successive PC being aligned along the direction of the maximum remaining variance in the data (Jensen, 2000). As the PCs are orthogonal, they represent independent variables that can be used in regression analysis. PCA also has the added advantage of eliminating noise represented in the lower components if they are excluded from further analysis. In this research, variable sets were created using only PCs with eigenvalues greater than 1.0 (Chapman et al., 1993), the remaining PCs being discarded as noise. The latter explained less than $2 \%$ of the variance in all cases. Three principal component analyses were carried out. The first PCA was run on all the spectral variables (only the raw spectral bands were used), the second on all the texture variables and the third on all the spectral and textural variables together.

PCA of all spectral measures produced three PCs, that of all texture measures 26 PCs and that of all texture and spectral measures together 27 PCs. Through an analysis of the factor loadings, it was discovered that only four of the original spectral and textural variables were significantly correlated $(\mathrm{p} \leq 0.05)$ to the PCs. This was done by looking at which variables were most heavily loaded on which factors. It was found that the 
correlations between that variables and the PC's were very high with respect to the four variables of the raw green spectral band (Raw Green), the Mean texture of $3 \times 3$ averaged green brightness (Mean_G_3), the Contrast texture of $3 \times 3$ thermal brightness (CON_TH_3) and the Variance texture of $3 \times 3$ averaged thermal brightness.

\subsection{Modeling Forest Canopy Closure Using Landsat Data}

Since the goal of this research was to determine if forest canopy closure can be modeled from Landsat imagery, linear regression analyses were applied using the various sets of $\mathrm{x}$ variables described above and SPSS Version 12.0 software.

Canopy closure measures derived from the three instruments were entered as the dependent variables while the spectral and textural measures were entered as the independent variables. Linear stepwise regression was implemented to determine if models could be developed to predict forest canopy closure from any combination of the image variables. In processing, the algorithm enters the $\mathrm{x}$ variable with the highest correlation with the dependent variable, followed sequentially by other $\mathrm{x}$ variables if their partial correlations contribute significantly to a model. The probability to enter was set at 0.05 and $p$ to exit was 0.10 . The models were evaluated with respect to the overall model significance ( $p$-value), coefficient of determination $\left(R^{2}\right)$, the standard error of estimate of the model and adjusted $\mathrm{R}^{2}$, which accounts for reduced degrees of freedom when variables are added to a model. Various combinations of image variables were tested in regressions as follows:

- All spectral variables

- All textures $(3 \times 3)$

- All spectral and texture variables 
- $\quad$ PCs with eigenvalues $>1$ for spectral, textural and both variable sets together

- Only those variables which were significantly correlated with canopy closure based on bivariate correlation analysis.

Before conducting the regressions, scatterplots of each of the variables against canopy closure were inspected to determine if any non-linear relationships existed that would require variable transformation. For most variables, no linear or non-linear trends were evident. For the few where trends were visible, they were obviously linear. The model residuals were also checked and were found to be uniform and normally distributed.

\subsection{Model Validation}

From the above analysis, the variables found to be consistently entered into models of canopy closure using all 30 plots were reused in ten subsequent regressions that included 25 randomly selected plots and five set aside for validation.

Assessment of the predictive capability of the models with all 30 plots was based on the resulting model standard error of estimate for canopy closure. Validation of the models with plots set aside was based on the average error as well as the average absolute error in predicting canopy closure using the model equation. 


\section{Chapter 4 Results}

Results are presented for comparison of the three forest canopy closure measurement methods followed by modeling of canopy closure using Landsat imagery.

\subsection{Comparison of the Three Measures of Canopy Closure}

The three forest canopy closure measurement methods, the sighting tube, Trac and hemispherical photography, were compared both qualitatively in terms of implementation procedures and quantitatively through correlation analysis.

\subsubsection{Qualitative comparison}

All three canopy closure measurement instruments used in this research have very distinctive operational advantages and disadvantages.

One of the least costly methods to measure forest canopy closure is the sighting tube. It is easy to carry, maintain and use, and measurements can be taken any time during the day. The main disadvantage of this instrument is the difficulty one has of aligning it vertically without some sort of mount or level. The observer cannot be certain that the correct reading is being taken each time and this can introduce error into the reading. Bias can also be introduced if the observer tends to point the instrument at one class more than the other (e.g. sky more than foliage). In dense foliage, small movements of the tube can change the reading from one class to the other. Bias may also occur if the locations at which the readings are taken are not objectively located. For example, if the operator selects locations visually, there may be a tendency to avoid measurements right next to a tree trunk or in heavy ground vegetation. Another disadvantage is that it is fairly time consuming to acquire the large number of samples required to adequately 
represent the spatial variation in the canopy. In a given plot, repeated sampling of all 30 locations occasionally produced large discrepancies in average percent forest canopy closure.

The Trac has the primary advantage of being able to measure PPFD (photosynthetic photon flux density), which can be used to produce many statistics pertaining to the architecture of the forest canopy. However, the conditions needed to collect the Trac data are relatively rare in Eastern Ontario where the humidity for the summer is very high and cumulous clouds often start to fill the sky in the morning before the sun is at its zenith. The instrument itself is very delicate and has to be transported with great care. Due to this fragility, it can occasionally fail to collect data so it is necessary to carry a laptop into the forest to check the data for defects after every plot is completed. It is also very difficult to walk at a constant speed in a straight line in the forest due to low and sometimes dense ground vegetation, coarse woody debris, and nettle patches. Consequently, use of the Trac is very time consuming. Transects have to be marked in the forest before the measurement day, or at the least the same morning, and then one has to wait for breaks in the clouds to collect data. Often, data collection along a transect has to stop while a cloud passes over. In comparison with the nature of the radiance detected by the other two instruments, the Trac senses sun rays that pass through the canopy at the given sun zenith and azimuth. The length of canopy traversed is greater than that of the other two vertically-oriented instruments (hemispherical photography and sighting tube) because, in the study area at approximately $45^{\circ} \mathrm{N}$ latitude, the Trac is sensing light that is coming through the forest canopy at an oblique angle producing a greater path through the canopy. Thus, it was expected that Trac closure values would be 
consistently greater than those measured with both the sighting tube and hemispherical photos.

Perhaps the most difficult instrument of all to operate is the hemispherical camera. It requires the transport of a lot of equipment (the camera, hemispherical lens, tripod and other miscellaneous items such as extra batteries, memory cards and light metres) through the forest just before dusk or dawn in order to produce images without sunflecks under diffuse illumination. The setup time in each plot is considerable and, like the sighting tube, the tripod cannot be set up right beside a tree trunk because the resultant image would not be an accurate representation of the forest canopy. In selecting an exposure, there is no guarantee that the images captured will be of use when viewed on a larger screen where the transition between black and white (foliage and sky, respectively) may not be as distinct as needed for an accurate measurement of canopy closure. There are also many computer processing steps which need to be strictly and carefully monitored in deriving canopy closure from the original image. "For hemispherical photography, errors can occur at any stage of image acquisition, digitization, or analysis. Because many steps are involved, accumulated error can become great unless strict quality control is exercised. A severe error at any stage can invalidate the final results, even if other steps are performed with little error" (HemiView User Manual, 2004). This said, the processing can be tailored to the needs of the researcher. For example, one can choose the degree (from 0 to 90 ) of the zenith angle for calculation of forest canopy closure. However, the greater the angle used, the more the influence of branches and trunks and the longer the radiance path through the canopy. Hemispherical photography is especially advantageous compared to the other methods 
because one can archive the images and thus compare canopy closure over time. One can also use hemispherical photography to calculate PPFD and derive LAI. For the view angles selected, radiation was not measured at angles as oblique as that of the Trac, and it was not as subject to visual bias as was the sighting tube. Thus, hemispherical photo closure values seemed more typical for the forests of the study, never being close to $100 \%$ as they often were for the other two sensors.

\subsubsection{Quantitative comparison}

Table 4 shows the canopy closure estimates derived using each method for all 30 plots. Each hemispherical photo estimate is the average of three measurements taken at different locations within the plots. Each sighting tube estimate is an average of 30 observations at different locations within the plot. The Trac canopy closure is the single value derived from the three transects traversing each plot.

All of these canopy closure estimates, except those of hemispherical photography with view angles of less than $31^{\circ}$, seem to vary directly with each other, with Trac canopy closure being consistently higher by approximately $10 \%$ than hemispherical photography values and by $5 \%$ over the sighting tube values.

Most of the hemispherical photography canopy closure estimates increased with increased angle of view. The average difference in forest canopy closure between the $4^{\circ}$ and $31^{\circ}$ angles was $4.45 \%$, between $13^{\circ}$ and $31^{\circ}, 3.18 \%$ and between $22^{\circ}$ and $31^{\circ}$, $1.35 \%$. The $4^{\circ}$ measure does not seem to be a very good representation of canopy closure because the values differ more with the other three angles than the others do among themselves. The area within which canopy closure is measured in the $0-4^{\circ}$ angle is so 
small that it is highly influenced by moderate to large gaps (or lack thereof) that may not be representative of the overall canopy gap fraction.

An illustration of how large gaps in the forest canopy can influence the measurement of forest canopy closure can be seen by examining plot 7 of landscape 29 in Table 4. In this plot, the hemispherical photograph was taken beneath a gap in the canopy in two out of the three cases which were then averaged to create the canopy closure percent estimates in Table 4. The sizes of these gaps were large enough to fill most of the view angle from $0-22^{\circ}$ but they did not extend beyond that. The resulting canopy closure percent estimates derived using either the manual or the DHP method with angles less than $0-22^{\circ}$ were much lower than the estimate of canopy closure for 0 $31^{\circ}$. For this plot, the estimate of $84 \%$ canopy closure for the $0-31^{\circ}$ angle is more representative of the actual canopy closure and is closer to both the other canopy closure percent estimates measured by the sighting tube (93.9\%) and the Trac (94.2\%).

The sighting tube values were $100 \%$ for seven cases and often very close to $100 \%$, which is impossible in these types of forests. Thus, as with the unrealistically high values obtained from the Trac (illustrated by the 13 plots in which the Trac produced canopy closure values equal to or above $95 \%$ ), the sighting tube cannot be considered to be reliable in forest cover measurement.

After assessing all of these points for each instrument, it was concluded that the best method of measuring forest canopy closure is hemispherical photography, both for the reasons stated and because the other two methods have flaws that are expected to reduce their accuracy in closure measurement. With the sighting tube, there is the 
inconsistency of vertical pointing as well as the bias included in the measurement by the researcher.

Table 4. Canopy closure percent estimates derived using each method for all 30 plots.

\begin{tabular}{|c|c|c|c|c|c|c|c|c|c|c|c|}
\hline LS & Plot & $\begin{array}{l}\text { Man. } \\
\text { Avg. } \\
\text { Cov. } \\
4^{\circ} \\
\end{array}$ & $\begin{array}{l}\text { Man. } \\
\text { Avg. } \\
\text { Cov. } \\
13^{\circ}\end{array}$ & $\begin{array}{l}\text { Man. } \\
\text { Avg. } \\
\text { Cov. } \\
22^{\circ}\end{array}$ & $\begin{array}{l}\text { Man. } \\
\text { Avg. } \\
\text { Cov. } \\
31^{\circ}\end{array}$ & $\begin{array}{l}\text { DHP } \\
\text { Avg. } \\
\text { Cov. } \\
4^{\circ} \\
\end{array}$ & $\begin{array}{l}\text { DHP } \\
\text { Avg. } \\
\text { Cov. } \\
13^{\circ} \\
\end{array}$ & $\begin{array}{l}\text { DHP } \\
\text { Avg. } \\
\text { Cov. } \\
22^{\circ}\end{array}$ & $\begin{array}{l}\text { DHP } \\
\text { Avg. } \\
\text { Cov. } \\
31^{\circ}\end{array}$ & $\begin{array}{l}\text { Trac } \\
\text { Cover }\end{array}$ & $\begin{array}{c}\text { Sighting } \\
\text { Tube } \\
\text { Avg. } \\
\text { Cover }\end{array}$ \\
\hline 10 & 5 & 67.9 & 79.8 & 80.3 & 80.1 & 66.4 & 76.7 & 78.7 & 77.9 & 95.8 & 81.8 \\
\hline 10 & 6 & 84.2 & 77.8 & 79.8 & 80.5 & 82.3 & 76.4 & 76.6 & 76.9 & 92.3 & 84.9 \\
\hline 10 & 7 & 88.9 & 90.6 & 88.5 & 86.6 & 89.9 & 88.7 & 86.1 & 84.6 & 93.8 & 93.9 \\
\hline 10 & 9 & 55.7 & 54.2 & 66.1 & 72.1 & 55.2 & 54.3 & 66.3 & 70.1 & 96.8 & 75.8 \\
\hline 10 & 10 & 68.8 & 71.4 & 75.9 & 77.3 & 67.3 & 69.8 & 75.1 & 76.3 & 84.2 & 78.8 \\
\hline 28 & 2 & 84.1 & 71.2 & 80.8 & 83.8 & 84.6 & 72.3 & 79.8 & 81.5 & 95.0 & 90.9 \\
\hline 28 & 5 & 75.8 & 80.7 & 78.7 & 69.7 & 73.7 & 76.6 & 75.1 & 67.3 & 91.4 & 69.7 \\
\hline 28 & 6 & 52.7 & 58.9 & 58.9 & 59.7 & 53.9 & 61.3 & 60.8 & 62.0 & 76.0 & 60.6 \\
\hline 29 & 1 & 92.3 & 88.0 & 93.3 & 93.7 & 91.6 & 86.0 & 92.3 & 92.9 & 98.8 & 100 \\
\hline 29 & 2 & 94.9 & 86.2 & 85.2 & 88.5 & 92.4 & 83.3 & 82.5 & 85.5 & 95.6 & 97.0 \\
\hline 29 & 3 & 94.6 & 86.3 & 81.7 & 87.6 & 94.2 & 85.1 & 80.5 & 85.6 & 98.2 & 97.0 \\
\hline 29 & 4 & 88.4 & 91.4 & 88.9 & 92.1 & 83.6 & 87.1 & 87.9 & 90.7 & 98.4 & 100 \\
\hline 29 & 7 & 26.9 & 54.1 & 68.9 & 84.0 & 31.4 & 57.8 & 70.3 & 83.2 & 94.2 & 93.9 \\
\hline 30 & 1 & 94.5 & 87.7 & 88.0 & 89.2 & 91.2 & 84.4 & 88.4 & 89.1 & 96.3 & 100 \\
\hline 30 & 2 & 75.0 & 79.8 & 84.7 & 86.3 & 73.4 & 77.9 & 83.3 & 84.2 & 93.7 & 93.9 \\
\hline 30 & 4 & 83.5 & 89.2 & 83.2 & 82.5 & 82.8 & 87.5 & 79.9 & 80.1 & 95.5 & 84.9 \\
\hline 30 & 7 & 63.7 & 72.7 & 78.2 & 78.6 & 61.0 & 69.2 & 75.7 & 76.0 & 95.0 & 81.8 \\
\hline 30 & 8 & 66.4 & 90.6 & 90.9 & 82.8 & 65.0 & 86.7 & 88.5 & 81.8 & 94.6 & 84.9 \\
\hline 5 & 5 & 87.6 & 90.7 & 95.5 & 95.1 & 87.1 & 90.9 & 94.6 & 94.4 & 99.3 & 100 \\
\hline 5 & 7 & 92.3 & 90.5 & 94.3 & 93.2 & 92.2 & 89.4 & 93.1 & 91.2 & 97.5 & 100 \\
\hline 5 & 9 & 97.4 & 93.2 & 88.4 & 87.5 & 96.7 & 91.8 & 86.1 & 85.1 & 94.4 & 97.0 \\
\hline 6 & 2 & 74.3 & 82.5 & 85.3 & 90.4 & 72.5 & 80.5 & 83.7 & 88.9 & 97.2 & 100 \\
\hline 6 & 3 & 68.3 & 71.5 & 67.8 & 67.3 & 64.8 & 68.3 & 65.7 & 65.3 & 77.4 & 66.7 \\
\hline 6 & 5 & 91.9 & 83.6 & 86.9 & 88.2 & 91.1 & 83.5 & 85.7 & 87.0 & 93.6 & 97.0 \\
\hline 6 & 9 & 95.3 & 95.1 & 85.1 & 85.1 & 94.1 & 93.0 & 84.5 & 84.2 & 91.3 & 93.9 \\
\hline 6 & 10 & 85.6 & 82.2 & 84.6 & 86.8 & 84.0 & 80.4 & 82.2 & 84.5 & 93.8 & 93.9 \\
\hline 8 & 2 & 96.4 & 87.5 & 82.9 & 85.9 & 92.6 & 86.4 & 84.9 & 86.9 & 93.5 & 93.9 \\
\hline 8 & 4 & 58.9 & 56.9 & 59.2 & 63.3 & 53.5 & 60.9 & 60.4 & 64.1 & 72.5 & 60.6 \\
\hline 8 & 5 & 90.2 & 93.5 & 92.1 & 92.9 & 83.4 & 88.1 & 87.3 & 89.6 & 91.9 & 100 \\
\hline 8 & 9 & 54.3 & 51.1 & 69.6 & 73.4 & 51.9 & 51.5 & 66.2 & 69.5 & 92.0 & 75.8 \\
\hline
\end{tabular}

LS = Landscape

Plot $=$ Plot number within the landscape

Manual $=$ Canopy closure calculated using the thresholds implemented by the researcher DHP = Canopy closure calculated using the thresholds implemented by the software

Avg. $=$ Refers to the fact that the canopy closure was averaged from three hemiphotos, or 30 sighting tube measurements

$4^{\circ}, 13^{\circ}, 22^{\circ}, 30^{\circ}=$ Refers to the angles on each side of nadir within which canopy closure was measured 
With the Trac, the main problem is the oblique angle at which canopy closure is measured. A path length correction could be applied to Trac data but, as stated earlier, a correction solely based on viewing geometry was deemed to be too simplistic to justify its application here. Such a correction should consider leaf orientation distribution, canopy height heterogeneity, and other factors such as understory intercepted along the oblique path length. Therefore, even though hemispherical photography may have a longer and more involved method of processing, it was determined to be the most rigorous and useful way of measuring forest canopy closure.

Table 5 shows that all canopy closure measurements were significantly correlated with each other $(\mathrm{p}<0.05)$. Correlations of both the Trac and sighting tube data with hemispherical photography increased with photo view angle. This was expected with respect to the Trac because the largest hemispherical view angle of $0-31^{\circ}$ is the closest to the average sun zenith angle of $32^{\circ}$ that was associated with the Trac measurements. The lowest two correlations were between hemispherical photography estimates in the $0-4^{\circ}$ angle and Trac estimates because of the large difference between their view angles. For the sighting tube, it was unexpected that the lowest correlations would be with hemispherical photography estimates with the $4^{\circ}$ angle. One explanation may be that many sighting tube readings taken throughout the plot are more representative of the gap fraction in the canopy than the three hemispheric estimates taken from this narrow angle. Taken over the whole plot, the many sighting tube readings produce a canopy closure estimate closer to that of the hemispherical photography for the $31^{\circ}$ view angle (at three locations in each plot). 
Table 5. Correlation matrix for all methods of canopy closure measurement

\begin{tabular}{|c|c|c|c|c|c|c|c|c|c|c|}
\hline $\begin{array}{l}\text { Canopy closure } \\
\text { Measurement } \\
\text { Acquisition Method }\end{array}$ & $\begin{array}{r}\text { DHP_Avg } \\
\text { Cov } 4^{\circ}\end{array}$ & $\begin{array}{r}\text { DHP_Avg } \\
\text { Cov_13 } \\
\end{array}$ & $\begin{array}{r}\text { DHP_Avg } \\
\text { Cov_22 } \\
\end{array}$ & $\begin{array}{r}\text { DHP_Avg } \\
\text { Cov_31 }\end{array}$ & $\begin{array}{c}\text { Man._Avg } \\
\text { Cov_4 }\end{array}$ & $\begin{array}{r}\text { Man._Avg } \\
\text { Cov_13 }\end{array}$ & $\begin{array}{r}\text { Man._Avg } \\
\text { Cov_22 } \\
\end{array}$ & $\begin{array}{r}\text { Man._Avg } \\
\text { Cov_31 } \\
\end{array}$ & TRAC & $\begin{array}{c}\text { Sighting } \\
\text { tube }\end{array}$ \\
\hline DHP_Avg_Cov $4^{\circ}$ & 1 & & & & & & & & & \\
\hline DHP_Avg_Cov_13 ${ }^{\circ}$ & 0.853 & 1 & & & & & & & & \\
\hline DHP_Avg_Cov_22 & 0.754 & 0.894 & 1 & & & & & & & \\
\hline DHP_Avg_Cov_31 ${ }^{\circ}$ & 0.640 & 0.733 & 0.904 & 1 & & & & & & \\
\hline Man._Avg_Cov_4 $4^{\circ}$ & 0.992 & 0.853 & 0.767 & 0.663 & 1 & & & & & \\
\hline Man. Avg Cov $13^{\circ}$ & 0.858 & 0.990 & 0.887 & 0.748 & 0.867 & 1 & & & & \\
\hline Man._Avg_Cov_22 & 0.749 & 0.882 & 0.986 & 0.919 & 0.767 & 0.889 & 1 & & & \\
\hline Man._Avg_Cov_31 ${ }^{\circ}$ & 0.633 & 0.734 & 0.887 & 0.989 & 0.658 & 0.760 & 0.923 & 1 & & \\
\hline TRAC & $0.409^{*}$ & 0.497 & 0.728 & 0.798 & $0.448^{*}$ & 0.486 & 0.722 & 0.755 & 1 & \\
\hline sighting tube & 0.624 & 0.688 & 0.848 & 0.983 & 0.654 & 0.709 & 0.872 & 0.977 & 0.79 & 1 \\
\hline
\end{tabular}

$\mathrm{P} \leq 0.01$ for all but two values

* $\mathrm{P}=0.025$

$* * \mathrm{P}=0.013$

$\mathrm{n}=30$ 
For Trac estimates versus sighting tube estimates, the correlation is moderate but highly significant. The tube measured vertical canopy closure at many locations on the three transects in each plot, while the Trac measured oblique canopy closure on the same transects. For the southern transect, the Trac signal was generated from radiance transmitted through the canopy outside the plot, while for the other two transects, radiance detected by the Trac traversed the canopy within the plot close to the locations of the sighting tube measurements.

Figures 10 to 12 show regressions for each pair of canopy closure instruments. The Trac cover estimates were much greater than tube estimates for the range up to $95 \%$ canopy closure (Figure 12) and greater than photo estimates for the whole range of canopy closure values (Figure 10). Figure 11 shows that the sighting tube estimates were greater than photo estimates except below about $70 \%$ canopy closure, but more data would be needed to confirm this. The residuals in Figures 10 and 11 increase as closure decreases which means that the relations are less stable and less valid for more open forests. It is clear that at the higher end of canopy closure, the instruments provide related estimates, while at the lower end, they respond differently from one another. Or, it could also be simply due to more abundant data at the upper ends of the distribution due to the generally high canopy closure within the plots.

Correlations such as these are all based on the assumptions that the trend is linear, that the residuals are normally distributed around the regression line and that there is homoscedacity which means that there is equal variance in $y$ for different values of $x$. In this case, there is a lack of homoscedacity but the residuals appear to remain normally distributed around the regression line. To ensure that the $\mathrm{R}^{2} \mathrm{~s}$ were not underestimated, 
the data in Figures 10 and 12 were normalized by squaring them and it was found that the $\mathrm{R}^{2} \mathrm{~S}$ only increased by 0.02 and 0.04 respectively. Therefore, although the data do not quite seem to meet the requirements of the method due to the obvious heteroscedacity, the differences in $\mathrm{R}^{2} \mathrm{~s}$ are so small that this method was determined to be adequate for this analysis.

Since the two figures whose graphs with the greatest heteroscedascity are the ones which correlate Trac with hemispherical photography (Figure 10) and the sighting tube (Figure12) respectively, it is possible that this might be due to the arrangement of trees within the forest canopy and the way in which their arrangement would affect the measurement of canopy closure with the Trac, an issue which was discussed in section 2.1.

From the quantitative analysis above, hemispherical photos were deemed to be better for estimation of closure than the other two instruments. A final comparison of thresholding methods as well as view angles was conducted. Hemispherical photography at an angle of $31^{\circ}$ was deemed the best for image modeling since the diameter of the forest canopy included within $31^{\circ}$ would be exactly $30 \mathrm{~m}$, the same as a Landsat pixel (the average heights of the trees being $25 \mathrm{~m}$ ). The decision of which thresholding method to select was more difficult. The automatic thresholding was deemed to be better in a study by Nobis and Hunziker (2004). The manual and DHP hemispherical photography estimates were very similar at all view angles.

The average differences in canopy closure estimates between both the Trac and sighting tube with hemispherical photography (manually thresholded) at $31^{\circ}$ were $-9.9 \%$ and $-5.5 \%$, respectively. The same average differences with respect to the DHP 
(automatically thresholded) hemispherical photography were $-11.4 \%$ and $-7.1 \%$, respectively. As these are not much different from each other, it was decided that neither method would be particularly advantageous.

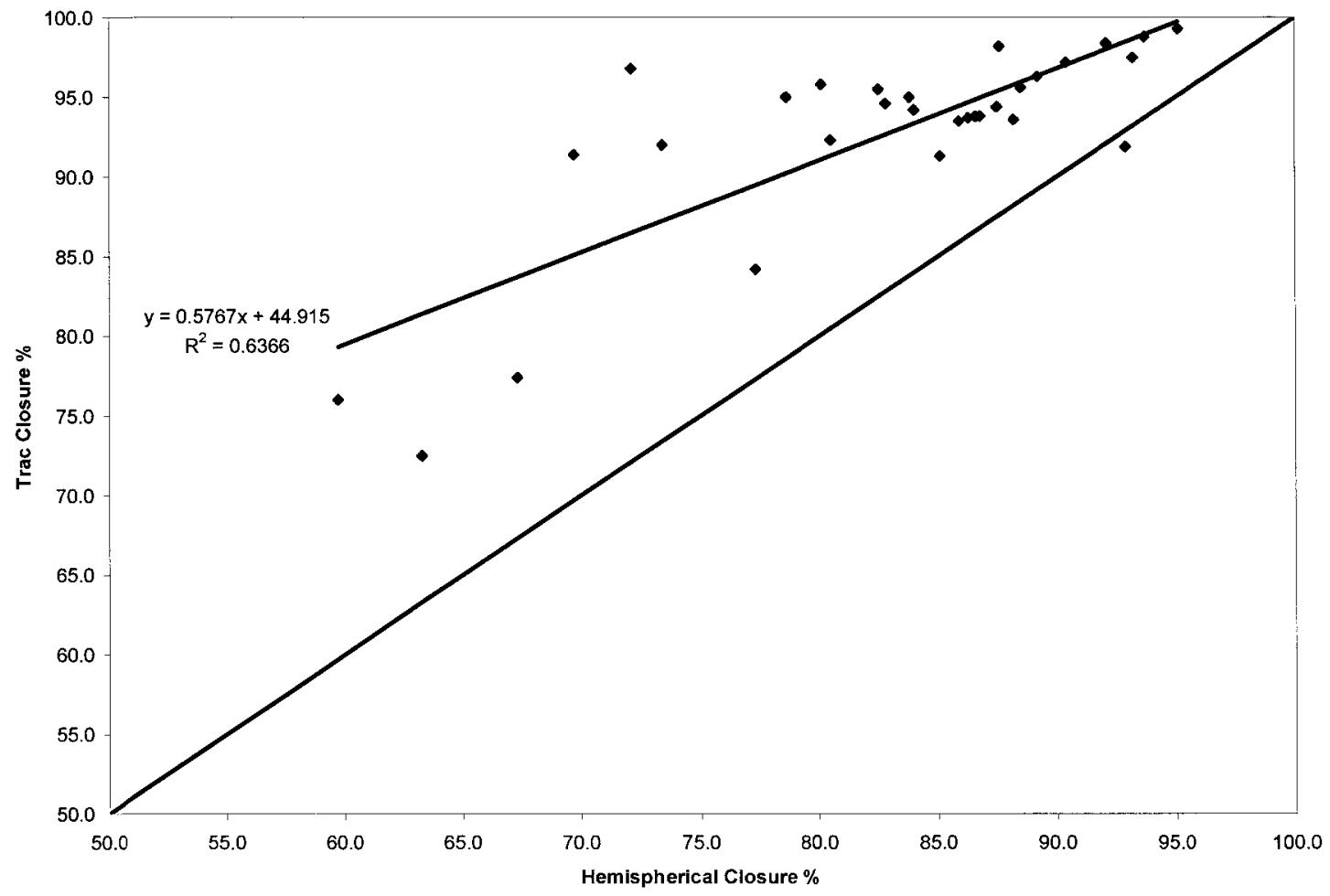

Figure 10. Average automated hemispherical canopy closure (0-31 degrees) vs. Trac canopy closure. A 1:1 line is also shown. 


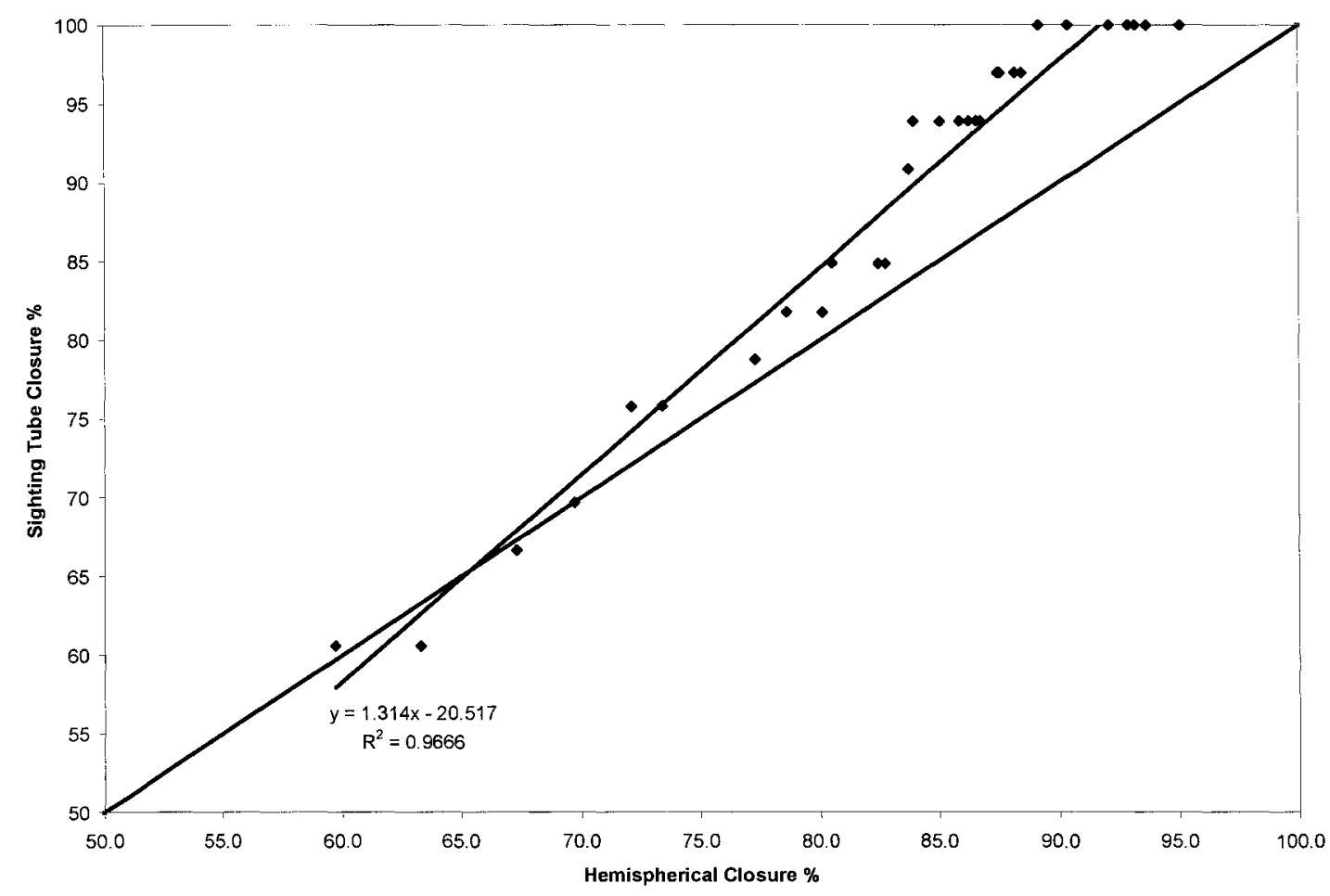

Figure 11. Average automated hemispherical canopy closure (0-31 degrees) vs. Sighting tube canopy closure. A 1:1 line is also shown.

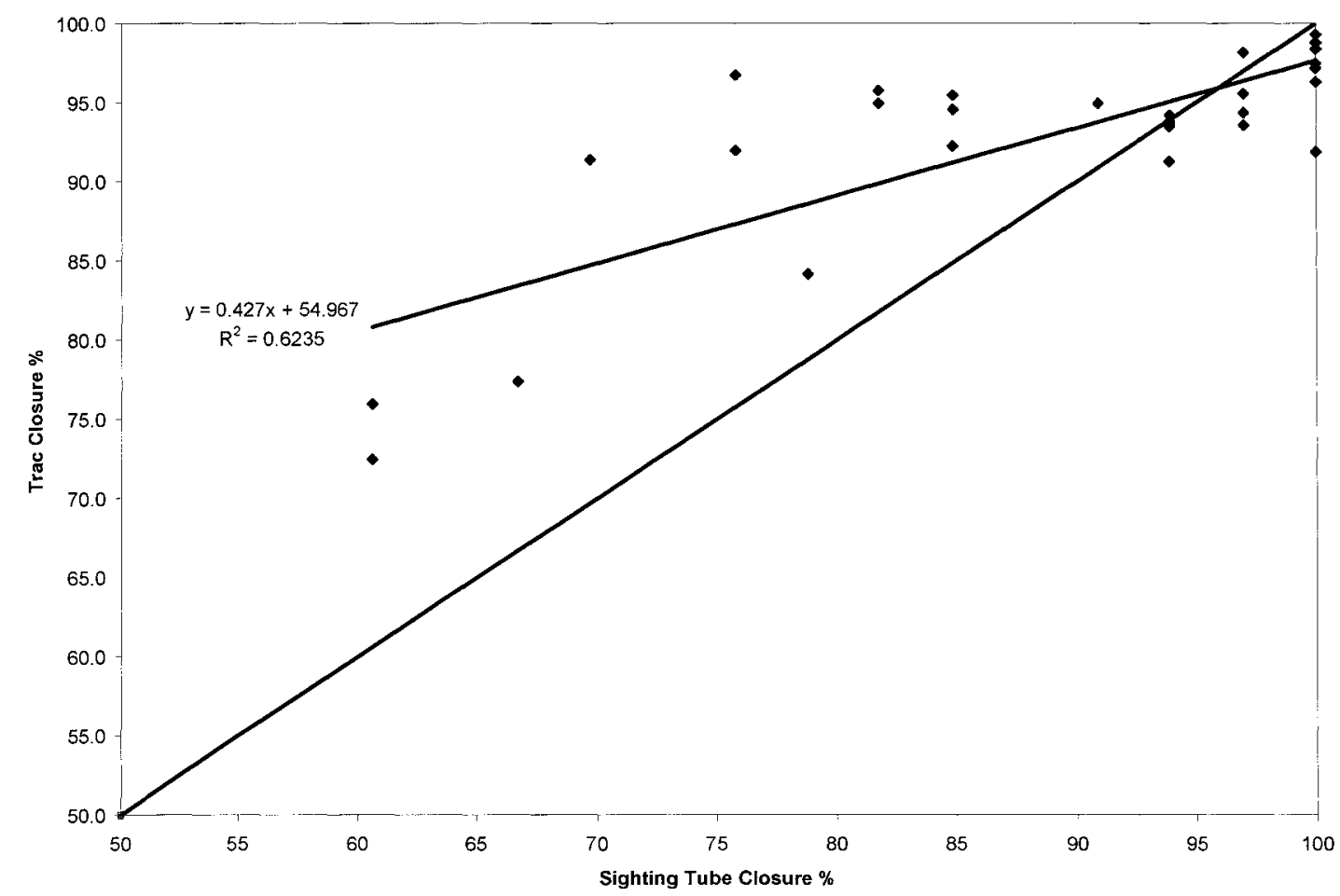

Figure 12. Sighting tube canopy closure vs. Trac canopy closure. A 1:1 line is also shown. 


\subsection{Modeling Forest Canopy Closure using Satellite Imagery}

\subsubsection{Bivariate correlations}

Bivariate correlation analysis of all image variables against all types of cover estimates showed generally weak relations. Table 6 gives the significant $(p \leq 0.05)$ correlations.

Table 6. Bivariate correlations for the textural and spectral image variables against canopy closure. Significant relations are $(\mathrm{p} \leq 0.05)$ shown in bold.

\begin{tabular}{|c|c|c|c|c|}
\hline & $\begin{array}{c}\text { MEAN_G_3 } \\
r / p\end{array}$ & $\begin{array}{c}\text { CON_TH_3 } \\
r / p\end{array}$ & $\begin{array}{c}\text { VAR_TH_3 } \\
r / p\end{array}$ & $\begin{array}{c}\text { RAW_Green } \\
\mathbf{R} / \mathbf{p}\end{array}$ \\
\hline $\begin{array}{l}\text { Man._Avg. } \\
\text { Cov._4 }^{\circ}\end{array}$ & $-0.17 / 0.36$ & $0.23 / 0.24$ & $0.20 / 0.29$ & $-0.10 / 0.62$ \\
\hline $\begin{array}{l}\text { Man._Avg. } \\
\text { Cov._13 }\end{array}$ & $-0.29 / 0.13$ & $0.17 / 0.35$ & $0.21 / 0.28$ & $-0.29 / 0.12$ \\
\hline $\begin{array}{l}\text { Man._Avg. } \\
\text { Cov._22 }\end{array}$ & $-0.32 / 0.08$ & $0.32 / 0.08$ & $0.33 / 0.08$ & $-0.39 / 0.03$ \\
\hline $\begin{array}{l}\text { Man._Avg. } \\
\text { Cov._31 }\end{array}$ & $-0.41 / 0.02$ & $0.33 / 0.07$ & $0.33 / 0.07$ & $-0.42 / 0.02$ \\
\hline $\begin{array}{l}\text { DHP_Avg. } \\
\text { Cov._4 }\end{array}$ & $-0.21 / 0.27$ & $0.22 / 0.24$ & $0.19 / 0.32$ & $-0.16 / 0.41$ \\
\hline $\begin{array}{l}\text { DHP_Avg. } \\
\text { Cov._13 }^{\circ}\end{array}$ & $-0.31 / 0.09$ & $0.17 / 0.37$ & $0.19 / 0.31$ & $-0.38 / 0.07$ \\
\hline $\begin{array}{l}\text { DHP_Avg. } \\
\text { Cov._22 }\end{array}$ & $-0.35 / 0.06$ & $0.36 / 0.05$ & $0.37 / 0.05$ & $-0.42 / 0.02$ \\
\hline $\begin{array}{l}\text { DHP_Avg. } \\
\text { _Cov__31 }\end{array}$ & $-0.41 / 0.02$ & $0.36 / 0.05$ & $0.36 / 0.05$ & $-0.45 / 0.01$ \\
\hline Trac_Cov. & $-0.37 / 0.04$ & $0.30 / 0.10$ & $0.33 / 0.07$ & $-0.47 / 0.01$ \\
\hline $\begin{array}{l}\text { Sighting } \\
\text { tube Cov. }\end{array}$ & $-0.39 / 0.03$ & $0.30 / 0.11$ & $0.29 / 0.12$ & $-0.41 / 0.02$ \\
\hline
\end{tabular}

All the other bivariate correlations had significance ( $\mathrm{p}$ values) of 0.3 or higher, including all spectral and texture PCs. This shows that there is no relation between most spectral and textural image information and canopy closure. Of the image variables in Table 6 , average $3 \times 3$ green brightness was correlated to more closure estimates and with generally higher correlation than were the other image variables. However, the negative relations indicate that green brightness decreased with increasing closure. This may be 
because shadows become darker in more closed canopies as less light penetrates adjacent crowns and there is less radiance from the understory (Seed and King, 2003). Similarly, the positive relations with Contrast and Variance textures were unexpected as textures at this scale should not increase with increasing closure. The only truly expected relation was that of mean texture, which decreased with increasing closure. A final, unexpected result was that thermal band texture was more related to closure than texture in other bands even though it has a larger pixel size.

From Table 6 , DHP $31^{\circ}$ is the only canopy closure measure that was significantly related to all four image measures. This result, in combination with results comparing the closure measurement methods in 3.1.1 and 3.1.2, led to the use of the DHP $31^{\circ}$ data in subsequent stepwise regression and removal of the other canopy closure measurements from further consideration.

\subsubsection{Stepwise regression of image variables against canopy closure}

Stepwise regression was conducted using the five data sets defined in Chapter Two, which consisted of all spectral data, all textural data, the spectral and textural data combined, the principal components of the combined spectral and textural data, and a regression using the four variables found to be significantly correlated with DHP $31^{\circ}$ canopy closure. These four variables were the Raw_Green, Mean_G_3, Con_TH_3 and VAR_TH_3. The results are given in Table 7 .

Using the spectral data, only the $3 \times 3$ average Raw_Green brightness was entered into a model. This reflects the bivariate correlation results as no other spectral data contributed additional significant variance. 
Table 7. Results of the stepwise regressions.

\begin{tabular}{|c|c|c|c|c|c|c|c|}
\hline $\begin{array}{c}\text { Image } \\
\text { Input } \\
\text { Variables }\end{array}$ & $\begin{array}{c}\text { Model } \\
\text { Variables }\end{array}$ & $R^{2}$ & $\begin{array}{c}\text { Adj. } \\
R^{2}\end{array}$ & $\begin{array}{l}\text { Standard } \\
\text { Error of } \\
\text { Estimate }\end{array}$ & $\begin{array}{c}\text { Change } \\
\text { in } R^{2}\end{array}$ & $\begin{array}{l}\text { Predictor } \\
\text { Sig. }\end{array}$ & $\begin{array}{c}\text { Overall } \\
\text { Sig. }\end{array}$ \\
\hline Spectral & Raw_Green & 0.20 & 0.17 & 8.1 & 0.20 & 0.01 & 0.01 \\
\hline Textural & 6 variables & 0.80 & 0.75 & 4.5 & $*$ & $*$ & 0.02 \\
\hline $\begin{array}{l}\text { Spec. \& } \\
\text { Tex. }\end{array}$ & 33 variables & 1.00 & 1.00 & 0.0 & $*$ & $*$ & 0.01 \\
\hline $\begin{array}{l}\text { Spec. \& } \\
\text { Tex. PCs }\end{array}$ & PC6_Tex & 0.16 & 0.13 & 8.3 & 0.16 & 0.03 & 0.03 \\
\hline \multirow{2}{*}{$\begin{array}{l}\text { Directed } \\
\text { Regression } \\
\text { All 30 } \\
\text { Plots Used }\end{array}$} & Raw_Green & \multirow[t]{2}{*}{0.41} & \multirow[t]{2}{*}{0.37} & \multirow[t]{2}{*}{7.1} & 0.20 & 0.00 & \multirow[t]{2}{*}{0.00} \\
\hline & CON_TH_3 & & & & 0.21 & 0.00 & \\
\hline
\end{tabular}

$*=$ Not reported due to the large number of variables

Adj. = Adjusted

Sig. $=$ Significance

The variance accounted for is very low, with an adjusted $R^{2}$ of only 0.17 . For the two regressions of all textural and all spectral + textural data, the resulting models have high explanatory power but with six and 33 variables, respectively. As the number of cases should be about ten times the number of model variables (Chapman and Munroe, 1993; Stevens, 1996; Steyerberg, et al., 2000) and these models suffered from high multocollinearity, they were not considered further. With this in mind, it was thought that principal component analysis could reduce the number of variables and maintain a high level of explanatory power. PCA was run on the textural data alone, the spectral data alone, and the spectral and textural data together. Stepwise regressions on these three sets of PCs only produced one model. For the spectral data alone, there were only three significant principal components and the stepwise regression failed to produce a significant model (therefore not shown in Table 7). The regression on the 26 texture principal components produced a model (also not shown in Table 7) that had only one variable accounting for very little variance in forest canopy closure (adjusted $R^{2}=0.13$ 
as shown in Table 7). The regression on all the PCs of both spectral and textural data combined produced a model with the same single variable that was produced using the PCs of all the textural data alone. The final regression conducted using only the four variables that were found to be highly correlated with canopy closure, namely Raw_Green (raw spectral values of the green band), Mean_G_3 (values produced using $3 \times 3$ Mean texture of the green band), $\mathrm{CON} \_\mathrm{TH} 33$ (values produced using $3 \times 3$ Contrast texture of the thermal band) and VAR_TH_3 (values produced using 3x3 Variance texture of the thermal band) produced considerably better results than any of the others, with a two variable model of moderate explanatory power (adjusted $R^{2}$ of 0.37 ). Therefore, it can be concluded that the model produced using those four variables which were highly correlated with canopy closure is the best that could be produced from all the spectral and textural data available.

\subsubsection{Stepwise regression models using plots set aside for validation.}

Since the directed regression produced the best model using all plot data, the same regression process was repeated but using fewer plots while setting some aside for validation. This regression was implemented ten times. Each time, 25 of the 30 plots were randomly chosen to produce the model and the remaining five were set aside for validation of the model. The results are given in Table 8 with the 30 plot model from Table 7 included for reference. In these stepwise regression models, two of the four image variables were always entered. Where Raw_Green was entered, Contrast or Variance texture was included but Mean texture (Mean_G_3) was too highly correlated with Raw_Green to be added. The average variance accounted for was greater than that of the 30 sample model. The average error of the ten models with validation data is close 
Table 8. Validation of the directed stepwise regressions.

\begin{tabular}{|c|c|c|c|c|c|c|c|c|c|c|}
\hline $\begin{array}{c}\text { Trial } \\
\text { Number }\end{array}$ & $\begin{array}{l}\text { Forest } \\
\text { Cover } \\
\end{array}$ & $\begin{array}{c}\text { Model } \\
\text { Variables } \\
\end{array}$ & $R^{2}$ & $\begin{array}{c}\text { Adj. } \\
R^{2}\end{array}$ & $\begin{array}{c}\text { Std. } \\
\text { Error of } \\
\text { Estimate } \\
\end{array}$ & $\begin{array}{l}\text { Change } \\
\text { in } R^{2}\end{array}$ & $\begin{array}{c}\text { Predictor } \\
\text { Sig. }\end{array}$ & $\begin{array}{c}\text { Overall } \\
\text { Sig. }\end{array}$ & $\begin{array}{l}\text { Avg. } \\
\text { Error }\end{array}$ & $\begin{array}{l}\text { Abs. } \\
\text { Error }\end{array}$ \\
\hline \multirow[t]{2}{*}{0} & $\begin{array}{c}30 \\
\text { Plots }\end{array}$ & RAW_Green & 0.41 & 0.37 & 7.07 & 0.202 & 0.001 & 0.004 & ------ & ----- \\
\hline & & CON_TH_3 & & & & 0.213 & 0.004 & & & \\
\hline \multirow{2}{*}{1} & $\begin{array}{c}25 \\
\text { Plots } \\
\end{array}$ & RAW_Green & 0.73 & 0.53 & 6.65 & 0.281 & 0.000 & 0.002 & 1.52 & 7.64 \\
\hline & & $\mathrm{CON} \mathrm{TH}_{3}$ & & & & 0.251 & 0.002 & & & \\
\hline \multirow{2}{*}{2} & $\begin{array}{c}25 \\
\text { Plots } \\
\end{array}$ & Mean_G_ 3 & 0.62 & 0.39 & 6.93 & 0.194 & 0.005 & 0.014 & 0.78 & 7.00 \\
\hline & & $\mathrm{CON}$ TH 3 & & & & 0.196 & 0.014 & & & \\
\hline \multirow{2}{*}{3} & $\begin{array}{c}25 \\
\text { Plots } \\
\end{array}$ & Mean_G_3 & 0.37 & 0.31 & 7.08 & 0.187 & 0.006 & 0.020 & 4.32 & 5.90 \\
\hline & & VAR TH 3 & & & & 0.182 & 0.020 & & & \\
\hline \multirow{2}{*}{4} & $\begin{array}{c}25 \\
\text { Plots } \\
\end{array}$ & RAW_Green & 0.44 & 0.39 & 7.60 & 0.211 & 0.004 & 0.007 & -0.54 & 3.53 \\
\hline & & $\mathrm{CON} \mathrm{TH}_{3} 3$ & & & & 0.226 & 0.007 & & & \\
\hline \multirow{2}{*}{5} & $\begin{array}{c}25 \\
\text { Plots }\end{array}$ & Mean_G_3 & 0.46 & 0.41 & 6.80 & 0.243 & 0.001 & 0.008 & -5.05 & 8.00 \\
\hline & & VAR TH 3 & & & & 0.212 & 0.008 & & & \\
\hline \multirow{2}{*}{6} & $\begin{array}{c}25 \\
\text { Plots } \\
\end{array}$ & RAW Green & 0.38 & 0.33 & 6.74 & 0.161 & 0.007 & 0.010 & 1.08 & 8.00 \\
\hline & & CON TH 3 & & & & 0.220 & 0.010 & & & \\
\hline \multirow{2}{*}{7} & $\begin{array}{c}25 \\
\text { Plots } \\
\end{array}$ & Mean G 3 & 0.51 & 0.47 & 7.05 & 0.323 & 0.000 & 0.008 & -3.58 & 6.46 \\
\hline & & VAR TH 3 & & & & 0.188 & 0.008 & & & \\
\hline \multirow[t]{2}{*}{8} & $\begin{array}{c}25 \\
\text { Plots } \\
\end{array}$ & RAW Green & 0.43 & 0.38 & 7.60 & 0.212 & 0.007 & 0.008 & -1.10 & 4.70 \\
\hline & & VAR TH 3 & & & & 0.217 & 0.008 & & & \\
\hline \multirow[t]{2}{*}{9} & $\begin{array}{c}25 \\
\text { Plots } \\
\end{array}$ & RAW_Green & 0.44 & 0.39 & 7.24 & 0.203 & 0.003 & 0.006 & 4.47 & 6.23 \\
\hline & & VAR TH 3 & & & & 0.238 & 0.006 & & & \\
\hline \multirow{2}{*}{10} & $\begin{array}{c}25 \\
\text { Plots } \\
\end{array}$ & RAW_Green & 0.44 & 0.39 & 6.77 & 0.168 & 0.004 & 0.004 & -4.23 & 7.91 \\
\hline & & $\mathrm{CON} \mathrm{TH}_{3} 3$ & & & & 0.269 & 0.004 & & & \\
\hline Average & & & 0.48 & 0.40 & 7.05 & & & & -0.23 & 6.54 \\
\hline Std. Dev. & & & 0.11 & 0.06 & 0.32 & & & & 3.16 & 1.43 \\
\hline
\end{tabular}

Avg. $=$ Average

Abs. $=$ Absolute

Sig. $=$ Significance

to zero indicating no bias. The average absolute error, which gives a better indication of how far the model error is from the field-measured canopy closure values regardless of direction of error, shows that there is potential to use these models to achieve canopy closure errors on the order of $7 \%$. Since the standard deviation (SD) of the 50 errors (calculated by subtracting the validation values from the values produced by the model) was 1.43 we can determine, with a confidence level of $95 \%$ that the error is between 
$4.14 \%(7-2(\mathrm{SD}))$ and $9.86 \%(7+2(\mathrm{SD}))$. Assuming that the actual error is the higher of the two, at approximately $10 \%$, then for a closure model estimate of $80 \%$, the $95 \%$ confidence interval would be $70 \%$ to $90 \%$. This is a reasonable absolute error level, but in relation to the range of hemispherical photography closure values used is this study (about 32\%), this represents a relative error of $22 \%$. 


\section{Chapter 5 Discussion}

In this chapter, the significant findings of the research, and the research limitations and recommendations are presented.

\subsection{Significant Findings}

This study consisted of two parts: comparison of three methods for field measurement of forest canopy closure, and regression-based modeling of closure using Landsat ETM+ spectral and spatial information. It was determined that hemispherical photography thresholded by the automated DHP method was more rigorous and was not as subject to bias or overestimation as were the Trac and sighting tube. Closure measured using this method in a $31^{\circ}$ zenith view angle was also related to more image-spectral and textural measures.

In image modeling, the results obtained from this study show moderate potential for mapping canopy closure in temperate hardwood forests using Landsat ETM+ imagery. There were very few image variables related to closure despite all the spectral and texture measures evaluated. The models show that green band brightness is the only spectral variable related to closure while three texture variables were significantly related.

Of these, Mean_G_3 was highly correlated with green brightness, so the two were never entered together in a model. The possible models therefore contain either green brightness + a thermal texture, or Mean texture + a thermal texture. It was unexpected that thermal band texture would be significant given the larger pixel size of the Landsat thermal imagery. An explanation for this cannot be provided at this time. Further research is required to determine if it is a spurious or real result. 
The average adjusted $\mathrm{R}^{2}$ of 0.40 for the 10 models produced in this study was higher than that of Gemmell et al. (2001) for their single-date analysis $\left(\mathrm{R}^{2}<0.22\right)$. They only used spectral data and found that the red and MIR band brightness gave the strongest correlations with closure. The accuracy of blind test points in this study was quite good, but no other studies have presented such data for comparison. The relatively low $\mathrm{R}^{2} \mathrm{~s}$ produced in this study mean that there is a lot of variance unaccounted for. This may be due in part to the relatively small number of plots (30) or narrow range of canopy closure values $(62-94 \%)$ or a combination of both factors.

This study used both spectral and textural data and found, primarily through the use of stepwise multiple regressions, that spectral data had very weak or nonexistent relationships with forest canopy closure but that the textural data did produce a model capable of predicting forest canopy closure with an average $R^{2}$ of 0.40 using the mean texture of the green band as well as the Variance and Contrast textures of the thermal band as the model variables. The validation of this model produced an average error of $-0.23 \%$ and an absolute error of $6.54 \%$ when 25 of the 30 plots were used to make the model and the remaining five were used as validation points. Although the predictive value of this model is questionable with the small range of forest canopy closure measurements, it nonetheless shows that further studies using larger ranges of forest canopy closure could produce very effective forest canopy closure models using this same technique.

\subsection{Limitations and Recommendations}

One of the main problems with modeling closure from imagery is that forest canopies are three dimensional with respect to all tree elements such as leaves, branches 
and stems whereas images are only two dimensional representations of all the radiance reflected back to the sensor. Radiance incident on the sensor is both that which is directly reflected from the top of the canopy and that which has penetrated the canopy to a certain extent and has then been reflected back to the sensor. There was an effort to control for this by selecting plots with limited understory between the height of the hemispherical camera $(175 \mathrm{~cm})$ and 10 metres but this was not feasible in all cases. This meant that there were many variations in the number of intermediate trees below the upper canopy which is typical in these temperate hardwood forests.

Higher resolution imagery might be better for modeling forest canopy closure. For example, J. Pasher (unpublished), using spectral data and sub-pixel fractions of Ikonos imagery, found an $\mathrm{R}^{2}$ of 0.59 with a standard error of $12 \%$ in a model of hemispherical photography closure with a zenith angle of $22.5^{\circ}$. Higher resolution imagery does, however, have much lower coverage and therefore is much more suited to targeted areas and not regional mapping which was the focus of this research. Woodcock et al. (1994), after evaluating a Landsat scale forest canopy reflectance model, recommended that a finer spatial resolution or multiple look angles be used to improve models of closure. It appears that high resolution sensors provide means to predict canopy closure well but only for small areas while Landsat predictions over larger areas would not be accurate enough for many applications. Thus, remote sensing at a scale intermediate between these two, such as with 5-10 m pixels and coverage in the 50-100 $\mathrm{km}$ range on each image side, may present the best compromise between accuracy and coverage. 
Another limitation with respect to this study was the lack of capability to sample more forests. Setting up plots and taking all these closure measurements by one individual was extremely time-consuming. Close to six weeks of daily field work were required to achieve a sample size of 30 . One of the goals of this research was to determine which of the field methods, the sighting tube, the Trac or hemispherical photography, provides closure values that are best modeled with Landsat ETM+ imagery. This meant that each plot was measured three times, once for each instrument, and 30 plots was the maximum that could be examined within the constraints of available time and labour. However, in future research, greater numbers of plots should be sampled, using only hemispherical photography since it was found to be the least biased method of measuring forest canopy closure.

Having more plots might allow the error levels to be assessed with more confidence, which was not possible within the scope of this thesis. Due to travel, set-up constraints, and the random sample taken, only seven landscapes were used so plots were often close to each other in a given landscape. This increases the spatial autocorrelation in the data and can inflate the accuracy of models as validation plots were often close to training plots. More sampling capability would allow greater distance between such plots and hence reduce the autocorrelation. More samples would also allow analysis of factors that contribute to the noise in the models such as outliers where understory or other factors had an impact.

The second main recommendation of this study is to select plots with a greater range of forest canopy closure that represents the full range found in the forests of Eastern Ontario. Regression models are typically stronger when a wide range in the $y$ 
variable can be measured. In this study, plots that were initially considered ranged from about $40-100 \%$ closure as previously measured using a sighting tube. However, not all plots could be assessed and the final random selection of 30 plots did not include the lowest closure values. More open canopy forests have radiance characteristics that are very different from those of closed canopy forests because more understory and ground vegetation become visible which may have other impacts on forest canopy closure models. Many of the world's forests have much lower closure (e.g. internationally, forests may be defined to include minimum closure of $10 \%$ and trees that only need potential to reach $5 \mathrm{~m}$ in height (FAO, 2002)), so more study of open forests is warranted.

An additional recommendation would be to use more (six or more per plot) hemispherical photos per plot and a double threshold method for the photos such as was done by Leblanc et al. (2004) and found to improve estimates of gap fraction. Larger patches of forest might also be chosen in which to situate the plots to avoid the possibility of incorporating non-forested areas when extracting textures with larger window sizes. Finally, models may improve using alternative methods of image analysis, such as vegetation indices or spectral unmixing to produce subpixel fractions of shadow, sunlit crown, and sunlit background. 


\section{Chapter 6 Conclusions}

The fact that this study was not entirely successful in modeling forest canopy closure does not detract from its legitimacy or validity but, instead, seriously questions the hypothesis that forest canopy closure can be adequately modeled using Landsat ETM+ in conjunction with spectral and textural measures using multiple linear regression.

Of the three instruments tested, the most successful in determining canopy closure was hemispherical photography thresholded by the automated DHP method. Based on the qualitative and theoretical analysis of measurement geometry, this method was shown to be more rigorous and not as subject to bias or overestimation as the Trac and sighting tube.

Forest canopy closure, however, remains one of the most important components involved in determining where forest flora and fauna will be found. A closure mapping method must be quick and cost-effective for it to be of any practical use. This study was designed to create such a model but met with limited success, which means that new methods must be developed to efficiently and effectively determine the forest canopy closure in temperate hardwood forests. These methods may or may not use Landsat ETM+ imagery successfully but, as the discussion suggests, with a larger range in canopy closure, more study plots, and using hemispherical photography thresholded with the DHP method, the methodology used in this study may prove useful in measuring forest canopy closure in the future. 


\section{$\underline{\text { References }}$}

Archibald, P.D., 1987. A continuous model for estimating lodgepole pine crown closure using Landsat TM data, digital elevation data and a forest cover GIS. Presented at the 11 th Canadian Symposium on Remote Sensing.

Asner, G.P., Keller, M., Pereira, R., and Zweede, J.C., 2002. Remote sensing of selective logging in Amazonia: Assessing limitations based on detailed field observations, Landsat ETM+, and textural analysis. Remote Sensing of the Environment 80: 483-496.

Balaster, N.J. and Marshall, J.D., 2000. Eight-year responses of light interception, effective leaf area index, and stemwood production in fertilized stands of interior douglas-fir. Canadian Journal of Forestry Research 30: 733-743.

Bellow, J.G. and Nair, P.K.R., 2003. Comparing common methods for assessing understory light availability in shaded-perennial agroforestry systems. Agricultural and Forest Meteorology 114: 197-211.

Breda, J. J., 2003. Ground-based measurements of leaf area index: a review of methods instruments and current controversies. Journal of Experimental Botany 54: 2403-2417.

Borghesio, L. and Ndang'ang'a, K.P., 2003. Habitat selection and the conservation status of fischer's tuaco on Unguja, Tanzania. Fauna and Flora International, Oryx 37: 444-453.

Brown, L., Chen, J. M., Leblanc, S. G., and Cihlar, J., 2000. A shortwave infrared modification to the simple ratio for LAI retrieval in boreal forests: An image and model analysis. Remote Sensing of Environment 71: 16-25.

Brown, N., Jennings, S., Wheeler, P. and Nabe-Nielsen, J., 2000. An improved method for the rapid assessment of forest understory light environments. Journal of Applied Ecology 37: 1044-1053.

Butson, C. 2005. Personal correspondence. Research Associate, Natural Resources Canada. chris.butson@ccrs.gc.ca

Chapman, J.M. and Monroe, C.B., 1993. An introduction to statistical problem solving in geography. Wm. C Brown Publishers. Dubuque, Iowa.

Charbonneau, N.C. and Fahrig, L., 2004. Influence of canopy closure and amount of open habitat in the surrounding landscape on proportion of alien plant species in forest sites. Ecoscience 11: 278-281. 
Chen, J.M., Palvlic, G., Brown, L., Cihlar, J., Leblanc, S.G., White, H.P., Hall, r.J., Peddle, D.R., King, D.J., Trofymow, J.A., Swift, E., Van der Sanden J. and Pellikka, P.K.E., 2002. Derivation and validation of Canada-wide coarse-resolution leaf area index maps using high-resolution satellite imagery and ground measurements. Remote Sensing of Environment 80: 165-184.

Chen, J.M. and Cihlar, J., 1995. Plant canopy gap-size analysis theory for improving optical measurements of leaf-area index. Applied Optics 34: 6211-6222.

Comeau, P.G., Gendron, F. and Letchford, T., 1998. A comparison of several methods for estimating light under paper birch mixedwood stand. Canadian Journal of Forest Research 28: 1843-1850.

Cosmopoulos, Y. and King, D.J., 2004. Temporal analysis of forest structural condition at an acid mine site using multispectral digital camera imagery. International Journal of Remote Sensing 25: 2421-2440.

Darwin, A.T., Ladd, D., Galdins, R., Contreras, T.A. and Fahrig, L., 2004. Response of understory vegetation to a major ice storm. Journal of the Torrey Botanical Society 131: 45-52.

Decagon Devices. 1987. Sunfleck ceptometer user's manual. Decagon Devices, Pullman, Wash.

Eklundh, L., Hall, K., Eriksson, H., Ardo, J. and Pilesjo, P., 2003. Investigating the use of Landsat thematic mapper data for estimation of forest leaf area index in southern Sweden. Canadian Journal of Remote Sensing 29: 349-362.

Englund, S.R., 2000. Evaluation of digital and film hemispherical photography and spherical densiometry for measuring forest light environments. Canadian Journal of Forest Research 30: 1999-2005.

Food and Agriculture Organization of the United Nations Proceedings: Second expert meeting on harmonizing forest-related definitions for use by various stakeholders. 2002.

Fensham, R.J., Fairfax, R.J., Holman, J.E. and Whitehead, P.J., 2002. Quantitative assessment of vegetation structural attributes from aerial photography. International Journal of Remote Sensing 23: 229-2317.

Fernandes, R.A., Miller, J.R., Chen, J.M. and Rubinstein, I.G., 2004. Evaluating imagebased estimates of leaf area index in boreal conifer stands over a range of scales using high-resolution CASI imagery. Remote Sensing of Environment 89: 200-216.

Franklin, S.E., Hall, R.J., Smith, L., and Gerylo, G.R., 2003. Discrimination of conifer height, age and crown closure classes using Landsat-5 TM imagery in the Canadian Northwest Territories. International Journal of Remote Sensing 24: 1823-1834. 
Gemmell F. M., 1995. Effects of forest cover, terrain, and scale on timber volume estimation with thematic mapper data in a rocky mountain site.

Gemmell, F., Varjo, J. and Stranstrom, M., 2001. Estimating forest cover in a boreal forest test site using thematic mapper data from two dates. Remote Sensing of Environment 77: 197-211.

Gemmell, F., Varjo, J., Strandstrom, M., and Kuusk, A., 2002. Comparison of measured boreal forest characteristics with estimates from TM data and limited ancillary information using reflectance model inversion. Remote Sensing of Environment 81: 365377.

giswww.pok.ibm.com/gps/glossary.html

Grubb, T. G., Ganey, J. L., and Masek, S. R., 1997. Canopy closure around nest sites of Mexican Spotted Owls in northcentral Arizona. Journal of Wildlife Management 61: 336-342.

Haddow, K.A., King, D.J., Pouliot, D.A., Pitt, D.G. and Bell, F.W., 2000. Early regeneration conifer identification and competition cover assessment using airborne digital frame camera imagery. The Forestry Chronicle, Special Issue on Remote Sensing, 76: 11-24.

Hale, S.E., and Brown, N., 2004. Use of the canopy-scope as a means of assessing canopy openness in plantation forests in Britain. Unpublished.

Hall, R.J., Fernandes, R.A., Hogg, E.H., Brandt, J.P., Butson, C., Case, B.S. and Leblanc, S.G., 2003. Relating aspen defoliation to changes in leaf area derived from field and satellite remote sensing data. Canadian Journal of Remote Sensing 29: 299-313.

Hall-Beyer, M., 2000. GLMC texture; a tutorial.

www.cas.sc.edu/geog/rslab/Rscc/mod6/6-5/texture/tutorial.html

Haralick, R.M., Shanmugan, K.S., and Dinstein, I., 1973. Textural and image

classification. IEEE Transactions on Systems Man and Cybernetics 6: 610-622.

Hodson, J., M. Henry, S. Hewitson and P. Quinby. 2004. Habitat use by American Marten in Temagami, Ontario: Preliminary implications for the Marten habitat suitability model and management guidelines. Forest Landscape Baselines Report No. 24, Ancient Forest Exploration \& Research, Toronto and Powassan, Ontario. 4 pp.

Hollenstein, K., Graham, R. L., and Shepperd, W. D., 2001. Biomass flow in western forests: Simulating the effects of fuel reduction and presettlement restoration treatment. Journal of Forestry 10:12-19. 
Hopkin, A. A., S. Greifenhagen and J. Holland (2001), Decay, stains, and beetles in ice storm-damaged forests: a review. The Forestry Chronicle 77(4):605-611.

Jennings, S.B., Brown, N.D. and Sheil, D., 1999. Assessing forest canopies and understory illumination: canopy closure, canopy cover and other measures. Journal of Forestry 1: 59-74.

Jensen, J.R., Ramset, E., Davis, B.A., and Thoemke, C.W., 1991. The measurement of mangrove characteristics in south-west Florida using SPOT multispectral data. Geocarto International 1: 1-21.

Kiema, J.B.K., 2002. Texture analysis and data fusion in the extraction of topographic objects from satellite imagery. International Journal of Remote Sensing 23: 767-776.

Krabill, W. and Maclean, G., 1984. Determining forest canopy characteristics using airborne laser data. Remote Sensing of Environment 15: 201-212.

Leblanc, S. G., 2004. Digital hemispherical photography manual, version 1.0. Canada Centre for Remote Sensing, Natural Resources Canada, Ottawa. 25 pages.

Leblanc, S. G., Chen, J. M. and Kwong, M., 2002. Trac manual, version 2.1. Canada Centre for Remote Sensing, Natural Resources Canada, Ottawa. 25 pages.

Lefsky, M.A., Hudak, A.T., Cohen, W.B. and Acker, S.A., 2005. Patterns of covariance between forest stand and canopy structure in the Pacific Northwest. Remote Sensing of Environment in press.

Lévesque, J. and King, D.J., 2003. Spatial analysis of radiometric fractions from highresolution multispectral imagery for modeling individual tree crown and forest canopy structure and health. Remote Sensing of Environment 84: 589-602.

Lillesand, T.M. and Kiefer, R.W., 2000. Remote sensing and image interpretation. Fourth Edition. John Wiley \& Sons, Inc. New York.

Machado, J.L. and Reich, P.B., 1999. Evaluation of several measures of canopy openness as predictors of photosynthetic photon flux density in deeply shaded coniferdominated forest understory. Canadian Journal of Forest Research 29: 1438-1444.

Martens, S.N., Ustin, S.L. and Rousseau, R.A., 1993. Estimation of tree canopy leaf area index by gap fraction analysis. Forest Ecology and Management 61: 91-108.

Moore, K.D., Jaffe, J.S. and Ochoa, B.L, 1999. Development of a new underwater bathymetric laser imaging system: L-bath. Journal of Atmospheric and Oceanic Technology 17: 1106-1117. 
Nobis, M. and Hunziker, U., 2005. Automatic thresholding for hemispherical canopy-photographs based on edge detection. Agricultural and Forest Meteorology 128: $243-250$.

Ohmann, J. L., 1992. Wildlife habitats of the north coast of California: New techniques for extensive forest inventory. Research Paper PNW-RP-440. Portland, OR: U.S. Department of Agriculture, Forest Service, Pacific Northwest Research Station. 48 p.

Pasher, J. personal communication on April 10, 2005 in the Carleton University Geomatics and Landscape Ecology Lab.

PCI Geomatica, 2004. www.pcigeomatics.com

Pellikka, P., 2001. Application of vertical skyward wide-angle photography and airborne video data for phenological studies of beech forests in the German Alps. International Journal of Remote Sensing 22: 2675-2700.

Pellikka, P.K.E., Seed, E.D. and King, D.J., 2000. Modelling deciduous forest ice storm damage using CIR aerial imagery and hemispheric photography. Canadian Journal of Remote Sensing 26: 394-405.

Pocewicz, A.L., Gessler, P.E. and Robinson, A.P., 2004. The relationship between effective plant area index and Landsat spectral response across elevation, solar insolation, and spatial scales in a northern Idaho forest. Canadian Journal of Forestry Resources 34: 465-480.

$\mathrm{Pu}, \mathrm{R} ., \mathrm{Xu}, \mathrm{B}$. and Gong, P., 2003. Oakwook crown closure estimation by unmixing Landsat TM data. International Journal of Remote Sensing, 24: 4433-4445.

Reynolds, R T., Graham, R. T., Reiser, M. H., Bassett, R. L., Kennedy, P. L., Boyce, D. A., Goodwin, G., Smith, R., and Fisher, E. L., 1992. Management recommendations for the Northern Goshawk in the southwestern United States. USDA Forest Service General Technical Report 217 Rocky Mountain Forest and Range Experiment Station, Fort Collins, Colorado, USA.

Rhoads, A.G., Hamburg, S.P., Fahey, T.J., Siccama, T.G. and Kobe, R., 2004. Comparing direct and indirect methods of assessing canopy structure in a northern hardwood forest. Canadian Journal of Forest Research 34: 584-591.

Robinson, M.W., 1947. An instrument to measure forest crown canopy closure. Forestry Chronicle 23: 222-225.

Schmidt, K.M., Menakis, J.P., Hardy, C.C., Hann, W.J., and Bunnell, D.L., 2002. Development of coarse-scale spatial data for wildland fire and fuel management. General Technical Report RMRS-GTR-87. Fort Collins, CO: U.S. Department of Agriculture, Forest Service, Rocky Mountain Research Station. 41 p. 
Seed, E.D. and King, D.J. 2003. Shadow brightness and shadow fraction relations with effective LAI: Importance of canopy closure and view angle in mixedwood boreal forest. Canadian Journal of Remote Sensing, Special Issue on Measurement and use of leaf area index in monitoring vegetated ecosystems 29: 324-335.

Stevens, J. M., 1996. Applied multivariate statistics for the social sciences, 3rd edn. Mahbah, NJ: Lawrence Erlbraum Associates.

Steyerberg, E.W., Eijkemans, M.J., Harrell, F.E. and Habbema, J.D., 2000. Prognostic modelling with logistic regression analysis: a comparison of selection and estimation methods in small data sets. Statistics in Medicine 19: 1059-1079.

Swallow, K. S., Howard, R. A. and Gutierrez, R.J., 1988. Snag preferences of woodpeckers foraging in a northeastern hardwood forest. Wilson Bulletin 100: 236-246.

Thomas, J.W., Forsman, E.D., Lint, J.B., Meslow, E.C., Noon, B.R., and J. Verner. 1990. A conservation strategy for the Northern Spotted Owl: A report of the interagency scientific committee to address the conservation of the Northern Spotted Owl. U.S. Department of Agriculture and U.S. Department of the Interior, Portland, Oregon.

Turner, D.P., Cohen, W.B., Kennedy, R.E., Fassnacht, K.S. and Briggs, J.M., 1999. Relationships between leaf area index and Landsat TM spectral vegetation indices across three temperate zone sites.

Vales, D.J. and Bunnell, F.L., 1985. Comparison of methods for estimating forest overstory cover. British Columbia, Ministry of Environment and Forests. IWIFR-20. Victoria, B.C.

Wang, G.G., 2000. Height growth of planted black spruce seedlings in response to interspecific vegetation competition: a comparison of four competition measures at two measuring positions. Canadian Journal of Forestry Resources 30: 573-579.

Welles, J.M., 1990. Some indirect methods of estimating canopy structure. Remote Sensing Reviews 5: 31-43.

White, M.A., Asner, G.P., Nemani, R.R., Privette, J.L. and Running, S.W., 2000. Measuring fractional cover and leaf area index in arid ecosystems: digital camera, radiation transmittance, and laser altimetry methods. Remote Sensing of Environment 74: $45-57$.

Wilson, B. A., and Ference, C.G., 2001. The influence of canopy closure on the detection of understory indicator plants in Kananaskis Country. Canadian Journal of remote sensing 27: 207-215. 
Woodcock, C.E., Collins, J.B., Gopal, S., Jababhazy, V.D., Li, X., Macomber, S., Rhyerd, S., Harward, V.J., Levitan, J., Wu, Y. and Warington, R., 1994. Mapping forest vegetation using Landsat TM imagery and a canopy reflectance model. Remote Sensing of Environment 50: 240-254.

Worledge, D., Honeysett, J.L., White, D.A., Beadle, C.L., and Hetherington, S.J., 1998. Scheduling irrigation in plantations of Eucalyptus globulus and E. nitens: a practical guide. Tasforests 10: 91-101.

www.gael.fr/eoqc/site/documents/download/GAEL-P157-SLP-001-04-01.pdf

Yang, J. and Prince S.D., 1997. A theoretical assessment of the relation between woody canopy cover and red reflectance. Remote Sensing of Environment 59: 428-439. 


\section{$\underline{\text { Appendix }}$}

Appendix 1. Coordinates of the 30 plots used for the study.

\begin{tabular}{|c|c|c|c|}
\hline $\begin{array}{c}\text { Landscape } \\
\text { Number }\end{array}$ & $\begin{array}{c}\text { Plot } \\
\text { Number }\end{array}$ & $\begin{array}{c}\text { Latitude } \\
\text { (degrees, minutes, } \\
\text { seconds) }\end{array}$ & $\begin{array}{c}\text { Longitude } \\
\text { (degrees, minutes, } \\
\text { seconds) }\end{array}$ \\
\hline 10 & 5 & $45^{\circ} 23^{\prime} 54.54^{\prime \prime}$ & $76^{\circ} 8^{\prime} 15.12^{\prime \prime}$ \\
\hline 10 & 6 & $45^{\circ} 23^{\prime} 58.26^{\prime \prime}$ & $76^{\circ} 8^{\prime} 17.1^{\prime \prime}$ \\
\hline 10 & 7 & $45^{\circ} 24^{\prime} 2.16^{\prime \prime}$ & $76^{\circ} 8^{\prime} 17.88^{\prime \prime}$ \\
\hline 10 & 9 & $45^{\circ} 23^{\prime} 55.98^{\prime \prime}$ & $76^{\circ} 8^{\prime} 28.98^{\prime \prime}$ \\
\hline 10 & 10 & $45^{\circ} 23^{\prime} 53.4^{\prime \prime}$ & $76^{\circ} 8^{\prime} 29.64^{\prime \prime}$ \\
\hline 28 & 2 & $45^{\circ} 20^{\prime} 28.86^{\prime \prime}$ & $76^{\circ} 20^{\prime} 15.18^{\prime \prime}$ \\
\hline 28 & 5 & $45^{\circ} 20^{\prime} 30.66^{\prime \prime}$ & $76^{\circ} 20^{\prime} 7.98^{\prime \prime}$ \\
\hline 28 & 6 & $45^{\circ} 20^{\prime} 39^{\prime \prime}$ & $76^{\circ} 20^{\prime} 7.32^{\prime \prime}$ \\
\hline 29 & 1 & $45^{\circ} 10^{\prime} 10.68^{\prime \prime}$ & $76^{\circ} 17^{\prime} 25.86^{\prime \prime}$ \\
\hline 29 & 2 & $45^{\circ} 10^{\prime} 7.32^{\prime \prime}$ & $76^{\circ} 17^{\prime} 36.18^{\prime \prime}$ \\
\hline 29 & 3 & $45^{\circ} 10^{\prime} 11.22^{\prime \prime}$ & $76^{\circ} 17^{\prime} 43.44^{\prime \prime}$ \\
\hline 29 & 4 & $45^{\circ} 10^{\prime} 16.5^{\prime \prime}$ & $76^{\circ} 17^{\prime} 36.12^{\prime \prime}$ \\
\hline 29 & 7 & $45^{\circ} 10^{\prime} 13.5^{\prime \prime}$ & $76^{\circ} 17^{\prime} 17.46^{\prime \prime}$ \\
\hline 30 & 1 & $45^{\circ} 14^{\prime} 47.82^{\prime \prime}$ & $76^{\circ} 18^{\prime} 40.14^{\prime \prime}$ \\
\hline 30 & 2 & $45^{\circ} 14^{\prime} 33.6^{\prime \prime}$ & $76^{\circ} 18^{\prime} 33.96^{\prime \prime}$ \\
\hline 30 & 4 & $45^{\circ} 14^{\prime} 23.52^{\prime \prime}$ & $76^{\circ} 18^{\prime} 24^{\prime \prime}$ \\
\hline 30 & 7 & $45^{\circ} 14^{\prime} 40.74^{\prime \prime}$ & $76^{\circ} 18^{\prime} 30.3^{\prime \prime}$ \\
\hline 30 & 8 & $45^{\circ} 14^{\prime} 38.1^{\prime}$ & $76^{\circ} 18^{\prime 22.92 "}$ \\
\hline 5 & 5 & $45^{\circ} 14^{\prime} 41.7^{\prime \prime}$ & $76^{\circ} 15^{\prime} 4.92^{\prime \prime}$ \\
\hline 5 & 7 & $45^{\circ} 14^{\prime} 36.12^{\prime \prime}$ & 76014'58.14" \\
\hline 5 & 9 & $45^{\circ} 14^{\prime} 35.82^{\prime \prime}$ & $76^{\circ} 14^{\prime} 54.6^{\prime \prime}$ \\
\hline 6 & 2 & $45^{\circ} 9^{\prime} 36.36^{\prime \prime}$ & $76^{\circ} 9^{\prime} 28.14^{\prime \prime}$ \\
\hline 6 & 3 & $45^{\circ} 9^{\prime} 34.62^{\prime \prime}$ & $76^{\circ} 9^{\prime} 39.24^{\prime \prime}$ \\
\hline 6 & 5 & $45^{\circ} 9^{\prime} 41.82^{\prime \prime}$ & $76^{\circ} 9^{\prime} 4.98^{\prime \prime}$ \\
\hline 6 & 9 & $45^{\circ} 9^{\prime} 51.71^{\prime \prime}$ & $76^{\circ} 9^{\prime} 49.32^{\prime \prime}$ \\
\hline 6 & 10 & $45^{\circ} 9^{\prime} 56.82^{\prime \prime}$ & $76^{\circ} 9^{\prime} 42.42^{\prime \prime}$ \\
\hline 8 & 2 & $45^{\circ} 24^{\prime} 55.26^{\prime \prime}$ & $76^{\circ} 11^{\prime} 13.74^{\prime \prime}$ \\
\hline 8 & 4 & $45^{\circ} 25^{\prime} 5.88^{\prime \prime}$ & $76^{\circ} 10^{\prime} 48.54 "$ \\
\hline 8 & 5 & $45^{\circ} 24^{\prime} 56.16^{\prime \prime}$ & $76^{\circ} 10^{\prime} 52.68^{\prime \prime}$ \\
\hline 8 & 9 & $45^{\circ} 24^{\prime} 44.58^{\prime \prime}$ & $76^{\circ} 10^{\prime} 40.2^{\prime \prime}$ \\
\hline
\end{tabular}

Note: Landscape and plot numbers correspond to those of the Department of Biology at Carleton University.

Hopkin, A. A., S. Greifenhagen and J. Holland (2001), Decay, stains, and beetles in icestorm-damaged forests: a review. The Forestry Chronicle 77(4):605-611. 
Appendix 2. Tree species noted in plots.

\begin{tabular}{|l|l|l|}
\hline Abrev & Genus and Species & Common Name \\
\hline ACRU & Acer rubrum & Maple, Red \\
\hline ACSA & Acer saccharum & Maple, Sugar \\
\hline BEAL & Betula alleghaniensis & Birch, Yellow \\
\hline BEPA & Betula papyrifera & Birch, White \\
\hline CACO & Carya cordiformis & Hickory, Bitternut \\
\hline FAGR & Fagus grandifolia & Beech, American \\
\hline FRAM & Fraxinus Americana & Ash, White \\
\hline FRNI & Fraxinus nigra & Ash, Black \\
\hline JUNI & Juglans nigra & Walnut, Black \\
\hline OSVI & Ostrya virginiana & Ironwood \\
\hline PIGL & Picea glauca & Spruce, White \\
\hline PIST & Pinus strobes & Pine, Eastern White \\
\hline POBA & Populus balsamifera & Poplar, Balsam \\
\hline POTR & Populus tremuloides & Aspen, Trembling \\
\hline PRSE & Prunus serotina & Cherry, Black \\
\hline QUAL & Quercus alba & Oak, White \\
\hline QURU & Querus rubra & Oak, Red \\
\hline THOC & Thuja occidentalis & Cedar, Eastern White \\
\hline TIAM & Tilia Americana & Basswood \\
\hline TSCA & Tsuga Canadensis & Hemlock, Eastern \\
\hline ULAM & Ulmus Americana & Elm, American \\
\hline
\end{tabular}


Appendix 3. Positions of the 34 points used to georeference the Landsat image.

\begin{tabular}{|c|c|c|c|c|c|c|c|}
\hline & & \multicolumn{2}{|c|}{ Residual } & \multicolumn{2}{|c|}{ Georef UTM } & \multicolumn{2}{|c|}{ Uncorrected } \\
\hline ID & $\begin{array}{c}\text { Error } \\
\text { (m) }\end{array}$ & $\begin{array}{c}\mathbf{X} \\
(\mathrm{m})\end{array}$ & $\begin{array}{c}Y \\
\text { (m) }\end{array}$ & $\begin{array}{c}\mathrm{X} \\
\text { (Easting) }\end{array}$ & $\begin{array}{c}\mathrm{Y} \\
\text { (Northing) }\end{array}$ & $\begin{array}{c}\mathbf{X} \\
\text { (Pixels) }\end{array}$ & $\begin{array}{c}Y \\
\text { (Pixels) }\end{array}$ \\
\hline 19 & 0.34 & 0.07 & -0.33 & 393744.110 & 5023621.410 & 56.53 & 404.59 \\
\hline 24 & 0.33 & 0.32 & -0.08 & 397424.170 & 5027200.480 & 179.36 & 285.70 \\
\hline 23 & 0.33 & 0.10 & 0.31 & 395322.970 & 5013619.910 & 109.02 & 738.36 \\
\hline 32 & 0.32 & -0.26 & -0.18 & 402561.650 & 5013418.880 & 349.69 & 744.69 \\
\hline 22 & 0.31 & -0.25 & -0.18 & 395933.020 & 5012926.630 & 128.97 & 760.97 \\
\hline 9 & 0.30 & 0.03 & 0.30 & 404429.910 & 4996738.740 & 411.98 & 1300.73 \\
\hline 3 & 0.27 & -0.22 & 0.16 & 406953.650 & 5027153.540 & 496.14 & 287.67 \\
\hline 8 & 0.27 & 0.27 & 0.00 & 406431.890 & 5004913.750 & 478.98 & 1028.20 \\
\hline 20 & 0.26 & 0.18 & 0.18 & 399669.790 & 5029043.040 & 254.02 & 224.64 \\
\hline 5 & 0.24 & -0.24 & -0.01 & 398959.740 & 5015835.090 & 229.80 & 664.33 \\
\hline$\overline{13}$ & 0.21 & -0.05 & -0.21 & 411443.310 & 4997769.730 & 645.45 & 1266.02 \\
\hline 26 & 0.21 & 0.17 & -0.12 & 411614.990 & 5013333.090 & 651.58 & 747.77 \\
\hline 2 & 0.18 & -0.16 & -0.09 & 402860.880 & 5031757.170 & 359.97 & 134.03 \\
\hline 16 & 0.18 & 0.14 & -0.11 & 399384.110 & 5017498.810 & 245.31 & 611.56 \\
\hline 29 & 0.18 & 0.09 & 0.16 & 419834.110 & 5020621.410 & 925.27 & 505.45 \\
\hline 31 & 0.18 & -0.18 & -0.01 & 412193.020 & 5023248.320 & 670.59 & 417.66 \\
\hline 6 & 0.18 & -0.18 & 0.01 & 401089.890 & 5010994.280 & 300.73 & 825.61 \\
\hline 36 & 0.17 & -0.05 & 0.17 & 394651.080 & 4997733.650 & 86.30 & 1267.30 \\
\hline 27 & 0.15 & 0.01 & -0.15 & 413530.850 & 5015159.290 & 715.23 & 686.95 \\
\hline 30 & 0.14 & 0.00 & 0.14 & 414214.710 & 5024998.930 & 738.11 & 359.55 \\
\hline 34 & 0.13 & 0.13 & 0.01 & 408953.840 & 5020565.160 & 563.02 & 506.98 \\
\hline 40 & 0.13 & 0.13 & 0.03 & 396448.030 & 5004029.290 & 146.39 & 1057.52 \\
\hline 21 & 0.13 & -0.09 & 0.10 & 396838.250 & 5013975.040 & 159.28 & 726.34 \\
\hline 28 & 0.13 & -0.02 & -0.13 & 417766.740 & 5018794.270 & 856.30 & 565.98 \\
\hline 15 & 0.12 & 0.05 & -0.11 & 406362.360 & 5009135.120 & 476.50 & 887.50 \\
\hline 38 & 0.11 & 0.03 & 0.11 & 406982.920 & 5018944.860 & 497.27 & 561.02 \\
\hline 35 & 0.11 & 0.09 & -0.06 & 398421.810 & 5001680.130 & 212.05 & 1135.70 \\
\hline 1 & 0.08 & 0.00 & 0.08 & 410083.050 & 5029814.410 & 600.59 & 199.03 \\
\hline 7 & 0.07 & -0.02 & -0.07 & 404395.130 & 5007214.610 & 410.91 & 951.47 \\
\hline 14 & 0.06 & -0.05 & 0.03 & 410303.010 & 5000552.650 & 607.52 & 1173.55 \\
\hline 25 & 0.06 & 0.00 & 0.06 & 399146.820 & 5028576.360 & 236.42 & 240.05 \\
\hline 39 & 0.04 & -0.04 & -0.01 & 403389.080 & 5010459.170 & 377.42 & 843.45 \\
\hline 4 & 0.03 & 0.02 & 0.02 & 403802.540 & 5024469.750 & 391.42 & 376.86 \\
\hline 18 & 0.01 & -0.01 & -0.01 & 396773.730 & 5022312.380 & 157.31 & 448.56 \\
\hline
\end{tabular}

